\title{
Distinct Basal Metabolism in Three Mouse Models of Neurodevelopmental Disorders
}

\author{
Caitlin Menzies, ${ }^{1,2}$ Shama Naz, ${ }^{3}$ David Patten, ${ }^{3}$ 'Thierry Alquier, ${ }^{4,5}$ Brian M. Bennett, ${ }^{6}$ and \\ Baptiste Lacoste ${ }^{1,2,7}$
}

https://doi.org/10.1523/ENEURO.0292-20.2021

\begin{abstract}
${ }^{1}$ Neuroscience Program, Ottawa Hospital Research Institute, Ottawa, Ontario K1H 8L6, Canada, ${ }^{2}$ Faculty of Medicine, Department of Cellular and Molecular Medicine, University of Ottawa, Ottawa, Ontario K1H 8M5, Canada, ${ }^{3} \mathrm{University}$ of Ottawa Metabolomics Core Facility, Faculty of Medicine, Ottawa, Ontario K1H 8M5, Canada, ${ }^{4} \mathrm{Montreal}$ Diabetes Research Center and Centre de Recherche du Centre Hospitalier de l'Université de Montréal (CRCHUM), Montréal, Quebec H1W 4A4, Canada, ${ }^{5}$ Department of Medicine, Université de Montréal, Montréal, Quebec H3T 1J4, Canada, ${ }^{6}$ Faculty of Health Sciences, Department of Biomedical and Molecular Sciences and Centre for Neuroscience Studies, Queens University, Kingston, Ontario K7L 3N6, Canada, and ${ }^{7}$ University of Ottawa Brain and Mind Research Institute, Ottawa, Ontario K1H 8M5, Canada
\end{abstract}

\begin{abstract}
Prevalence of metabolic disturbances is higher among individuals with neurodevelopmental disorders (NDDs), yet this association has been largely overlooked. Investigation into human disease remains challenging, as a complete pathophysiological understanding relies on accurate modeling and highly controlled variables. Genetically engineered mouse models are widely used to gain insight into the biology of human NDDs, but research focus has been on behavioral and neurophysiological abnormalities. Such models not only allow for evaluating usefulness in reproducing human features, including similarities and discrepancies with rodent phenotypes, but they also represent a unique opportunity to observe and quantify novel anomalies. Here, we present the first characterization and comparison of basal metabolism in three mouse models of NDDs, namely, Down syndrome (DS; Dp(16)Yey/+ mice), 16p11.2 deletion syndrome (16pDel; 16p11.2 df/+ mice), and fragile X syndrome [FXS; Fmr1 knock-out (KO) mice] and their wild-type (WT) counterparts. Using the Comprehensive Lab Animal Monitoring System (CLAMS) coupled to EchoMRI, as well as quantification of key plasma metabolites by liquid chromatography mass spectrometry (LC-MS), our in vivo study reveals that each mouse model expresses a unique metabolic signature that is sex-specific, independent of the amount of food consumed and minimally influenced by physical activity. In particular, we identify striking differences in body composition, respiratory exchange ratio (RER), caloric expenditure (CE), and concentrations of circulating plasma metabolites related to mitochondrial function. Providing novel insight into NDD-associated metabolic alterations is an essential prerequisite for future preclinical and clinical interventions.
\end{abstract}

Key words: 16p11.2 deletion syndrome; basal metabolism; Down syndrome; fragile X syndrome; neurodevelopmental disorders; plasma metabolites

\section{Significance Statement}

Most studies on neurodevelopmental and autism spectrum disorders (ASDs) have focused on neurophysiological mechanisms, yet these disorders are also associated with metabolic abnormalities in humans. Despite this known association, the link between metabolic imbalance and neurodevelopmental disorders (NDDs) has been largely overlooked, particularly in a fundamental research setting. Here, to address this knowledge gap, we performed the first systematic characterization of basal metabolism in mouse models of Down syndrome (DS), 16p11.2 deletion syndrome (16pDel), and fragile $X$ syndrome $(F X S)$, revealing unique metabolic signatures. This work provides a basis for future studies aimed at understanding mechanisms underlying metabolic dysfunction in NDDs. 


\section{Introduction}

Down syndrome (DS), 16p11.2 deletion syndrome (16pDel), and fragile X syndrome (FXS) are neurodevelopmental disorders (NDDs) of distinct genetic origins commonly associated with intellectual disability, developmental delay and autism spectrum disorders (ASDs; Miller et al., 2009; Hanson et al., 2010; McLennan et al., 2011; Shields et al., 2017). These particular NDDs are also associated with higher incidence of obesity, hypertension, hormonal dysfunction, heart defects and diabetes in comparison to the general population (McLennan et al., 2011; Miller et al., 2009; Croen et al., 2015; Shields et al., 2017; Flygare Wallén et al., 2018).

DS is caused by the presence of a third copy of chromosome 21. DS individuals display developmental delay and behavioral abnormalities (Mazurek and Wyka, 2015), and infants are often premature with low birthweights and heart defects leading to higher rates of neonate mortality (Vis et al., 2009; Mazurek and Wyka, 2015). Adult DS patients display obesity, insulin resistance, type 2 diabetes and decreased cardiovascular fitness (Vis et al., 2009; Mendonca et al., 2010; Real de Asua et al., 2014; Bertapelli et al., 2016; Shields et al., 2017). Despite experiencing multiple cardiovascular risk factors, DS individuals display lower rates of coronary artery disease and atherosclerotic damage, particularly among males (Vianello et al., 2013; Sobey et al., 2015). 16pDel originates from a hemizygous deletion at the 16p11.2 locus, resulting in the loss of $\sim 500 \mathrm{~kb}$ of DNA and haploinsufficiency of $\sim 30$ genes. Individuals harboring a 16p11.2 deletion are characterized by developmental delay and speech and language problems (Miller et al., 2009; Hanson et al., 2010; Horev et al., 2011). 16pDel is also associated with obesity and hyperinsulinaemic hypoglycemia (Kostopoulou et al., 2019). Male carriers are at higher risk of developing hypertension, whereas female carriers are at greater risk of developing type 2 diabetes (Croen et al., 2015; Flygare Wallén et al., 2018). Finally, FXS is caused by an expansion of CGG repeats in the promoter region of the FMR1 gene, which prevents production of fragile $X$ mental retardation protein (FMRP; Hoogeveen and Oostra, 1997; McLennan et al., 2011; Dahlhaus, 2018). FXS is one of the most common genetic causes of moderate-to-severe intellectual impairments but is also

This work was supported by Canadian Institutes of Health Research Grants 388805 (to B.L.) and 153013 (to B.M.B.) and by a Canadian Vascular Network Scholarship (C.M.). T.A. holds a salary Award from Fonds de Recherche Santé Québec. The Metabolomics Core Facility is supported by the Terry Fox Research Institute and the University of Ottawa.

Acknowledgements: We thank Dr. Mary-Ellen Harper for providing CLAMS cages; Dr. Julie St-Pierre, director of the uOttawa Metabolomics Core Facility; Dr. Matthew McDonald and Dr. Yan Burelle for feedback on this manuscript; Diane Anderson and Lihua Xue for technical assistance; the Behavioural Core Facility at uOttawa for assistance; and the Animal Care and Veterinary Services at uOttawa for guidance.

Correspondence should be addressed to Baptiste Lacoste at blacoste@ uottawa.ca.

https://doi.org/10.1523/ENEURO.0292-20.2021

Copyright (C) 2021 Menzies et al.

This is an open-access article distributed under the terms of the Creative Commons Attribution 4.0 International license, which permits unrestricted use, distribution and reproduction in any medium provided that the original work is properly attributed. associated with cardiovascular disease, obesity and hypertension (Crabbe et al., 1993; McLennan et al., 2011). As FXS is an X-linked syndrome, males are more commonly affected by FXS and typically display severe phenotypes. Females may harbor a heterozygous or homozygous FXS mutation (Linden et al., 1999; Bartholomay et al., 2019). Heterozygous females produce $\sim 80 \%$ of the FMRP levels and display mild phenotypes (Bartholomay et al., 2019). Rarer homozygous FXS females display phenotypes similar to male FXS individuals (Linden et al., 1999; Bartholomay et al., 2019).

Genetically engineered mouse models of DS, $16 \mathrm{pDel}$, and FXS have proven reliable tools in preclinical research (Bakker et al., 1994; Roubertoux and Carlier, 2010; Yang et al., 2015; Arbogast et al., 2016; Herault et al., 2017; Lovelace et al., 2018). To model DS in this study, we used $D p(16) Y e y /+$ mice that harbor trisomy of the orthologous genes of human chromosome 21 (Hsa21) that are present on Mmu16. These mice embody cognitive and developmental aspects reminiscent of human DS (Li et al., 2007; Roubertoux and Carlier, 2010; Yu et al., 2010; Herault et al., 2017). Heterozygous $16 p 11.2^{d f /+}$ mice represent a robust $16 \mathrm{pDel}$ model. They possess a deletion $(\sim 440 \mathrm{~kb}, 27$ genes) of the $7 \mathrm{qF} 3$ region of synteny conservation with the human 16p11.2 locus (Horev et al., 2011). Compared with their wild-type (WT) littermates, 16p11.2 df/+ mice display alterations including social interactions deficits and hyperactivity. These mice also display lower birthweight and decreased adiposity in adults, improved glucose tolerance, decreased leptin and free fatty acid levels, as well as cerebrovascular deficits (Horev et al., 2011; Portmann et al., 2014; Arbogast et al., 2016; Ouellette et al., 2020). Finally, Fmr1 ${ }^{-1-}$ knock-out (KO) mice are commonly used to model human FXS. Fmr1 ${ }^{-/-}$ mice harbor a KO allele of the Fmr1 gene located on the $\mathrm{X}$ chromosome. Although different from human FXS, Fmr1 ${ }^{-1-}$ mice lack FMRP expression (Hoogeveen and Oostra, 1997; Dahlhaus, 2018). $F m r^{-1-}$ mice display phenotypes including enhanced sensitivity to sensory stimuli, hyperactivity and physical characteristics (Hoogeveen and Oostra, 1997; Dahlhaus, 2018; Lovelace et al., 2018). These mice also display increased glucose tolerance and insulin sensitivity, as well as a shift toward lipid utilization (Leboucher et al., 2019).

Despite this context, a systematic characterization of basal metabolism in these three mouse models is lacking. Here, we performed a comprehensive assessment of basal metabolism of DS, 16pDel, and FXS mice by measuring body composition, physiological indices and selected plasma metabolites.

\section{Materials and Methods}

All animal procedures were conducted in accordance to guidelines of the Canadian Council on Animal Care.

\section{Animals}

$D p(16) Y e y /+$ "DS" mice (stock \#013530; mixed B6/129 background) were obtained from The Jackson Laboratory through the Cytogenetics and Down Syndrome Resource funded by a contract from the National Institute of Child Health and Human Development/National Institutes of Health (275201000006C-3-0-1). These mice harbor trisomy of the Mmu16 region of synteny with the Down 
Syndrome Critical Region (DSCR) on Hsa21 and carry 113 genes orthologous to genes on Hsa21 (Roubertoux and Carlier, 2010; Herault et al., 2017). 16p11.2 df/+ "16pDel" mice (Horev et al., 2011) were purchased from The Jackson Laboratory (stock \#013128; mixed B6/129 background). Heterozygous $16 p 11.2^{d f /+}$ mice possess a deletion of the $7 \mathrm{qF} 3$ region of synteny conservation with the human 16p11.2 locus. Fmr1 ${ }^{-1-}$ "FXS" mice (Bakker et al., 1994) were purchased from The Jackson Laboratory (stock \#004624, mixed FVB/129 background). These mice lack of expression of the $F m r 1$ gene product.

\section{Mouse husbandry}

All mice were bred in-house and housed maximum five per cage at room temperature with free access to water and food. Animals were maintained on Teklad Global 18\% Protein Rodent Diet (Harlan Laboratories, Teklad Diets) composed in part of $18.6 \%$ protein, $6.2 \%$ fat, $3.5 \%$ fiber, and $44.2 \%$ carbohydrates. Male $16 p 11.2^{d f /+}$ were crossed with WT females to obtain hemizygous $16 p 11.2^{d f /+}$ mice and WT littermates. $\mathrm{Fmr}^{-1-}$ males were bred with $\mathrm{Fmr}^{-1-}$ females to obtain $\mathrm{Fmr}^{-1-}$ progeny, and $\mathrm{Fmr}^{-1-}$ males were bred with FVB females to obtain $\mathrm{Fmrl}^{+/-}$heterozygous animals. Male Dp(16)Yey/+ mice were bred with female C57BL/6J mice (The Jackson Laboratory) to obtain hemizygous $D p(16) Y e y /+$ mice and WT littermates.

\section{Genotyping}

16p11.2 $2^{d f /+}$ mice and WT littermates were genotyped by PCR using the two following primers: $5^{\prime}-$ CCTCATGGACTAATTATGGAC-3' (forward) and 5'-CCA GTTTCACTAATGACACA-3' (reverse). Fmr1 ${ }^{-1-}$ mice and WT littermates were genotyped by PCR using the three following primers: 5'-CACGAGACTAGTGAGACGTG-3' (mutant forward), 5' -TGTGATAGAATATGCAGCATGTGA3' (WT forward), and 5'-CTTCTGGCACCTCCAGCTT-3' (common). $D p(16) Y e y /+$ mice and WT littermates were genotyped by PCR by a commercial vendor (Transnetyx) using proprietary primers.

\section{In vivo basal metabolism assessment}

Live, awake 10-week-old mice were weighed, placed in an enclosed tube and inserted into the Echo-MRI machine (EchoMRI-700, EchoMRI LLC) for 2-3 min. EchoMRI device employs magnetic resonance imaging to quantify total body weight, lean mass and fat mass in grams. Immediately following EchoMRI scanning, mice were individually housed at thermo-neutrality $\left(28^{\circ} \mathrm{C}\right)$ into Comprehensive Lab Animal Monitoring System (CLAMS) cages (CLAMS-CF and Oxymax software, Columbus Instruments) for metabolic measurements using indirect calorimetry (IC). A thermoneutral environment eliminates the need for the body to expend energy heating the body (Ramos-Jimenez et al., 2008; Gupta et al., 2017; Mtaweh et al., 2018). CLAMS cages are open circuit systems in which subjects breathe in gases that match atmospheric composition in an airtight acrylic chamber meant to mimic a home-cage, thermo-neutral environment with open access to food and water. CLAMS chambers are of the following dimensions. Livable area: 7 inches $(17.75 \mathrm{~cm})$ in diameter, 5.625 inches $(14.25 \mathrm{~cm})$ in ceiling height. Overall size with base and stand: 15 inches $(38 \mathrm{~cm})$ wide, 11 inches $(28 \mathrm{~cm})$ deep, 23 inches $(58.4 \mathrm{~cm})$ high. Animals were monitored daily for well-being. Equipment was calibrated before data collection by the University of Ottawa's Behavioural Core services and checked daily to ensure proper functioning. The CLAMS software automatically calculates output measures of volume of $\mathrm{O}_{2}$ consumption $\left(\mathrm{VO}_{2}\right)$, volume of $\mathrm{CO}_{2}$ production $\left(\mathrm{VCO}_{2}\right)$, respiratory exchange ratio (RER), caloric expenditure (CE), and food intake, as well as physical activity levels. The physiological effects of stress are minimized by allowing $24 \mathrm{~h}$ of habituation before data collection and minimal noise in the experimental area (Arch, et al., 2006; Ramos-Jimenez et al., 2008; Gupta et al., 2017).

IC is based on the principal that the conversion of carbohydrates, fats and proteins into chemical energy results in a substance-specific ratio of $\mathrm{O}_{2}$ required for catabolism of macronutrients and $\mathrm{CO}_{2}$ produced as a by-product (Ramos-Jimenez et al., 2008; Watson et al., 2014; Arch et al., 2006; Mtaweh et al., 2018). A number of factors must be considered for accurate IC measurement. Total CE measured by CLAMS is a composite of resting energy expenditure (REE), activity-related energy expenditure (AEE), and the thermic effect of feeding (TEF). REE is the energy required for the body to conduct the biochemical reactions required to sustain life and accounts for most bodily energy expenditure of mammals. AEE refers to energy used while performing elective movement, such as walking or running. TEF refers to the energy lost in the form of heat in the process of substrate utilization (Mtaweh et al., 2018). CLAMS cages provide an environment that minimizes the contribution of AEE and TEF. The CLAMS chambers where mice are housed are small and limit movement of the animal thus limiting AEE. TEF is mitigated by continuous feeding throughout the experiment and housing animals in a thermo-neutral environment (Ramos-Jimenez et al., 2008; Mtaweh et al., 2018).

Gas exchanges were measured every 26 min over a 72$\mathrm{h}$ period consisting of an initial 24-h habituation period followed by $48 \mathrm{~h}$ of data collection. The RER value represents the ratio of $\mathrm{VCO}_{2}$ produced to $\mathrm{VO}_{2}$ consumed. Total $\mathrm{CE}$ was calculated by a multi-step equation where a "calorific value," a standardized number of kilocalories generated per liter of $\mathrm{O}_{2}$ consumed, was first obtained by using RER. This calorific value was then multiplied by the $\mathrm{VO}_{2}$ of the organism to obtain the number of kilocalories used per unit of time. Food intake was measured as the cumulative amount of food consumed from the beginning of the experiment at each measurement period. Physical activity of animals was measured via an infrared beam system. Data are presented in terms of "beam breaks" where the number of times different beams were interrupted by the animal during the interval of time from one sampling session to the next.

CLAMS data were expressed both in absolute terms, and normalized to body weight and to lean mass, as recommended for comparison of populations with differential anthropomorphic characteristics or metabolic health status (Arch et al., 2006; Watson et al., 2014; Van Eersel et 
al., 2017; Mtaweh et al., 2018). Moreover, it is suggested that RER is calculated from absolute values of $\mathrm{O}_{2}$ and $\mathrm{CO}_{2}$ exchanges (Arch et al., 2006; Tschöp et al., 2011). Normalization of $\mathrm{CE}$ to lean mass facilitates comparison between groups of different body composition (Mtaweh, et al., 2018).

\section{Targeted plasma metabolome profiling}

Plasma levels of selected metabolites were quantified by liquid chromatography mass spectrometry (LC-MS). Sample temperature was maintained on ice or dry ice where possible, and all solvents were MS grade and preequilibrated to $-20^{\circ} \mathrm{C}$.

Metabolite extraction. Mouse saphenous vein blood $(200 \mu l)$ was collected in prechilled EDTA tubes, and centrifuged for $10 \mathrm{~min}$ at $4500 \mathrm{rpm}$ at $4^{\circ} \mathrm{C}$. Metabolites from $50 \mu \mathrm{l}$ of the resulting plasma were extracted with $600 \mu \mathrm{l}$ of a 1:1:1 mixture of methanol:acetonitrile:water. Samples were vortexed and $600 \mu \mathrm{l}$ of dichloromethane plus an additional 300- $\mu$ l water were added for liquid-liquid extraction. Samples were vortexed, incubated on ice for $10 \mathrm{~min}$ and then centrifuged for $10 \mathrm{~min}$ at $4000 \mathrm{rpm}$ at $4^{\circ} \mathrm{C}$. The resulting upper phase, consisting of polar metabolites, was separated into two fractions (for + ESI and -ESI injections), dried with a refrigerated $\left(-4^{\circ} \mathrm{C}\right)$ centrivap concentrator (Labconco) and stored at $-80^{\circ} \mathrm{C}$ before LC-MS analyses.

LC-MS metabolite quantification. Samples were resuspended with $75 \%$ acetonitrile, cleared by centrifugation and run on an Agilent 6545B Q-TOF mass spectrometer equipped with a 1290 Infinity II ultra-high performance LC (Agilent Technologies). Continuous internal mass calibration was executed using signals from purine [12,000 full width at half maximum (FWHM) resolution] and hexakis $(1 \mathrm{H}, 1 \mathrm{H}, 3 \mathrm{H}$-tetrafluoropropoxy) phosphazine $(24,000$ FWHM resolution). All study samples were randomized before analysis and run using both high and low $\mathrm{pH}$ hydrophilic interaction chromatography (HILIC-Z) in negative and positive ionization polarities, respectively. HILIC separation was obtained using the Poroshell 120 HILIC-Z column $(2.1 \times 100 \mathrm{~mm}, 2.7 \mu \mathrm{m}$; Agilent) and corresponding guard column. For negative ion mode chromatography, mobile phase A consisted of water and mobile phase $\mathrm{B}$ acetonitrile/water $(85 / 15, \mathrm{v} / \mathrm{v})$, both with $10 \mathrm{mM}$ ammonium acetate and $5 \mu \mathrm{m}$ medronic acid following the gradient: 0-2 min $96 \%$ B; 2-12 min linear gradient to $60 \%$ B; $12-15$ min linear gradient to $60 \% \mathrm{~B}, 15-16 \mathrm{~min}$ back to initial conditions and re-equilibrated in $96 \% \mathrm{~B}$ for $8 \mathrm{~min}$. For positive ion mode chromatography, mobile phase A consisted of water and mobile phase B acetonitrile/water (90/ $10, \mathrm{v} / \mathrm{v}$ ), both with $10 \mathrm{~mm}$ ammonium formate and $0.1 \%$ formic acid following the gradient: $0-1 \mathrm{~min} 98 \% \mathrm{~B}$; $1-$ 1.5 min linear gradient $90 \% \mathrm{~B}, 1.5-5$ min linear gradient $80 \%$ B, 5-8 min linear gradient 60\% B, 8-10.7 linear gradient $5 \%$ B, 10.7-12 min 98\% B, 12-12.7 min linear gradient to initial conditions and re-equilibrated for $3.6 \mathrm{~min}$. Autosampler and column temperature were maintained at $4^{\circ} \mathrm{C}$ and $30^{\circ} \mathrm{C}$, respectively. Samples were analyzed using $0.25 \mathrm{ml} / \mathrm{min}$ flow rate with an injection volume of $2 \mu \mathrm{l}$. MS detection settings were as follows: $\mathrm{N}_{2}$ drying gas temperature $200^{\circ} \mathrm{C}(-\mathrm{ESI})$ and $200^{\circ} \mathrm{C}(+\mathrm{ESI}) ; \mathrm{N}_{2}$ drying gas flow
$10 \mathrm{l} / \mathrm{min}$; sheath gas temperature $300^{\circ} \mathrm{C}$ (-ESI) and $225^{\circ} \mathrm{C}$ (+ESI); sheath gas flow $12 \mathrm{l} / \mathrm{min}$; nebulizer pressure 40 psig, capillary voltage $3000 \mathrm{~V}$, nozzle voltage $0 \mathrm{~V}$ and fragmentor voltage of $125 \mathrm{~V}$. MS data were collected for $\mathrm{m} / \mathrm{z}$ range of $60-1050$ at the acquisition rate of two spectra/s in the extended dynamic range mode $(2 \mathrm{GHz})$.

Metabolite identification and analysis. Metabolite identification was confirmed by exact mass, retention time and subsequent MS/MS fragmentation of metabolite standards and quality control samples. These identifications correspond to Metabolomics Standards Initiative identification level 1 (Sumner et al., 2007). A targeted list of metabolites was quantified (relative quantification) by external standard calibration curves with Mass Hunter Quant (Agilent).

\section{Statistics}

No statistical methods were used to predetermine sample size. Sample size ( $n=10$ per sex/genotype) was similar to previous reports (Horev et al., 2011; Portmann et al., 2014; Arbogast et al., 2016). Researchers were blind to genotype throughout data collection and analysis. In whisker box plots, boxes represent interquartile range (IQR), the median value is represented by a line through the box, and whiskers represent maximum and minimum values. In linear graphs, the line represents the mean and shadow represents SEM. Group differences were analyzed by two-way ANOVA and a Sidak's multiple comparisons post hoc test. Statistical significance, depicted by asterisks in plots, was considered when $p<0.05$. All statistical tests were performed using GraphPad Prism 9.0 Software.

\section{Results}

\section{Body composition of DS, 16pDel, and FXS mice measured by EchoMRI}

In humans, DS, $16 \mathrm{pDel}$, and FXS are all associated with alterations in body composition, including altered adipose tissue content and body size (Vis et al;, 2009; Horev et al., 2011; McLennan et al., 2011; Real de Asua et al., 2014; Gimeno-Ferrer et al., 2018). We first sought to examine body composition of the corresponding mouse models using EchoMRI to acquire quantitative measures of weight, lean mass and fat mass. No significant difference in weight, lean or fat mass was measured between $D p(16)$ $\mathrm{Yey} /+$ mice and their WT littermates (Fig. 1A), but a main effect of sex was detected for body weight $\left(F_{(1,18)}=63.09\right.$; $p<0.0001)$ and lean mass $\left(F_{(1,18)}=271.6 ; p<0.0001\right)$. We found that $16 p 11.2^{d f /+}$ mice weighed significantly less and had significantly lower proportions of lean mass compared with their WT littermates (Fig. 1B). The Fmr1 ${ }^{-1-}$ mice, however, weighed more and had higher lean and fat mass content when compared with their WT counterparts (Fig. 1C). As the mutation in Fmr1 underlying FXS is Xlinked, females may be either homozygous or heterozygous for the mutation (Linden et al., 1999). We therefore included heterozygous $\mathrm{Fmr1}^{+/-}$females in our study. There was no difference in weight, lean or fat mass between female $\mathrm{Fmrl}^{+/-}$and WT mice (Fig. 1C). These 

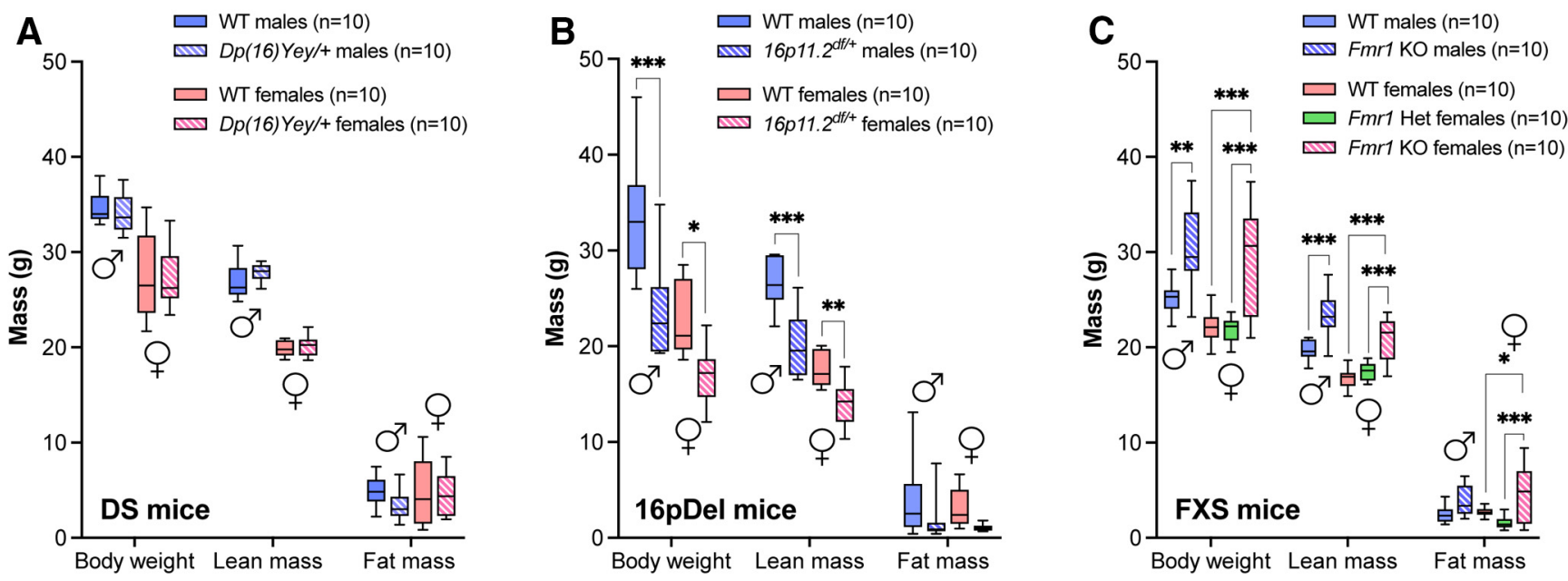

Figure 1. Analysis of body weight, lean mass, and fat mass in DS, $16 \mathrm{pDel}$, and FXS mice by EchoMRI. $\boldsymbol{A}$, Weight, lean mass, and fat mass $(\mathrm{g})$ of WT and Dp(16)Yey/+ male and female mice. B. Weight, lean mass, and fat mass (g) of WT and 16p11.2df/+ male and female mice. C, Weight, lean mass, and fat mass (g) of WT and Fmr1 KO (homo/heterozygous) male and female mice. WT, wild type; DS, Down syndrome; 16pDel, 16p11.2 deletion syndrome; FXS, fragile X syndrome. All data are whisker boxes (min to max, center line indicating median; $n=10$ animals per group). Asterisks depict significant differences between groups; ${ }^{*} p<0.05$, ${ }^{* *} p<0.01,{ }^{* \star *} p<0.001$ (two-way ANOVA and Sidak's post hoc test). ${ }^{\star}$ : males; + : females.

results demonstrate that genetic variations associated with DS, $16 \mathrm{pDel}$, and FXS in mice affect body weight, lean mass, and fat mass in a distinct manner.

\section{Basal metabolism indices measured by CLAMS in DS, 16pDel, and FXS mice}

Physiologic measures for each mouse model were then collected over a 48-h period (i.e., two day/night cycles) by housing mice in the CLAMS. Data were averaged over a 24-h cycle. CLAMS cages allow for a tight control of environmental factors, such as temperature, that could confound metabolic calculations. Body composition data obtained from the EchoMRI (body weight or lean mass) were used to normalize CLAMS-generated metabolic data (see Materials and Methods).

Body composition and metabolic variables are highly influenced by food intake and engagement in physical activity (qualitatively and quantitatively; Vis et al;, 2009; Mazurek and Wyka, 2015; Bertapelli et al., 2016; Peretti et al., 2019). To account for the influence of food intake on body composition and subsequent metabolic indices, all mice were fed the same chow diet and the cumulative amount of food consumed by each animal was measured over the duration of the experiment. No significant difference in food consumption was found in all three mouse models (Fig. 2A-C). Physical activity (i.e., number of horizontal laser beam breaks) of each animal was also recorded in CLAMS cages. Activity levels were largely similar between mutant and WT mice from all models (Fig. $2 D-F$ ). We only detected a main effect of sex for FXS mice (day: $F_{(1,18)}=17.48 ; p<0.001 ;$ night: $F_{(1,18)}=4.835$; $p<0.05)$ and an interaction between sex and genotype for DS mice at night $\left(F_{(1,18)}=5.758 ; p<0.05\right)$ and a slight, albeit significant, difference was found between $\mathrm{Fmr}^{-1-}$ males and their WT counterparts at night (Fig. 2F). Hence, these data suggest that differences identified in our study are not because of feeding behaviors and are minimally influenced by activity levels. We thus hypothesized that metabolic differences observed hereafter result from changes in basal energy metabolism.

When collecting and analyzing CLAMS data on $\mathrm{VO}_{2}$, we found that $\mathrm{Dp}(16) \mathrm{Yey} /+$ males consumed more $\mathrm{O}_{2}$ than females and WT males at night (Fig. 3A). No difference was detected among body weight-normalized values (Fig. 3D); however, when normalized to lean mass, $D p(16) Y e y /+$ females appeared to consume less $\mathrm{O}_{2}$ during the day compared with sex-matched WT littermates (Fig. 3G).

$16 p 11.2^{\text {dff }+}$ mice consumed less $\mathrm{O}_{2}$ than their WT counterparts, a difference more pronounced in females (Fig. 3B). Interestingly, when normalized to body weight or lean mass, a male-specific increase in $\mathrm{O}_{2}$ consumption was observed among 16p11.2 df/+ mice (Fig. 3E,H). Conversely, $\mathrm{Fmr1}^{-1-}$ mice consumed more $\mathrm{O}_{2}$ than their sex-matched WT littermates (Fig. 3C). When normalized to body weight or lean mass, $F m r^{-I}$ females appeared to consume less $\mathrm{O}_{2}$ than their WT counterparts (Fig. 3F,I). Similar $\mathrm{VO}_{2}$ was found between $\mathrm{Fmr}^{+/-}$and WT females (Fig. 3C,F,I). These results demonstrate that rates of $\mathrm{O}_{2}$ consumption are inconsistent between the DS, 16pDel, and FXS mouse models, and that these phenotypes are sex specific.

The CLAMS also measure fluctuations in $\mathrm{CO}_{2}$ production $\left(\mathrm{VCO}_{2}\right)$, which also reflects changes in resting metabolism (Farinatti et al., 2016; Patel et al., 2020). In absolute values for the DS model, females produced overall slightly more $\mathrm{CO}_{2}$ than their male counterparts (Fig. 4A). Lean mass-normalized $\mathrm{VCO}_{2}$ values revealed that $D p(16) \mathrm{Yey} /+$ females produced significantly more $\mathrm{CO}_{2}$ than their WT counterparts during the day (Fig. 4G). In absolute values, $16 p 11.2^{d f /+}$ females produced significantly less $\mathrm{CO}_{2}$ than their WT littermates (Fig. 4B). However, weight- 


\section{A DS mice}
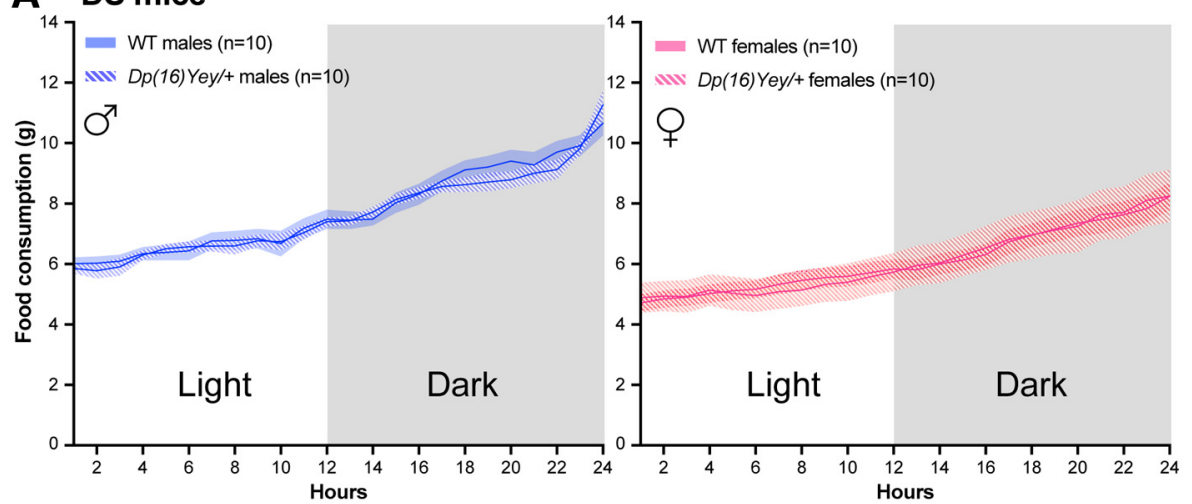

\section{B 16pDel mice}
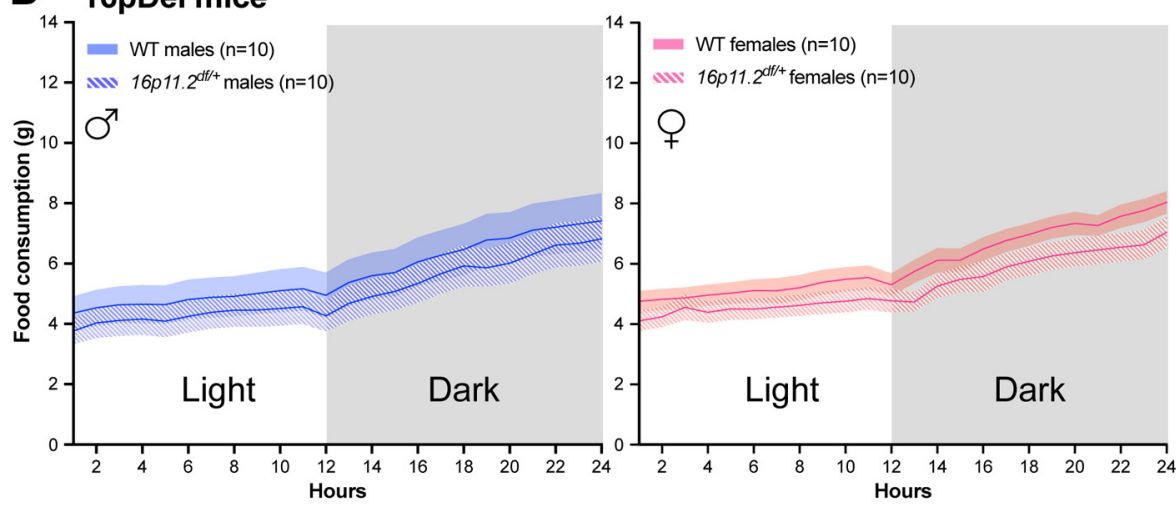

\section{FXS mice}
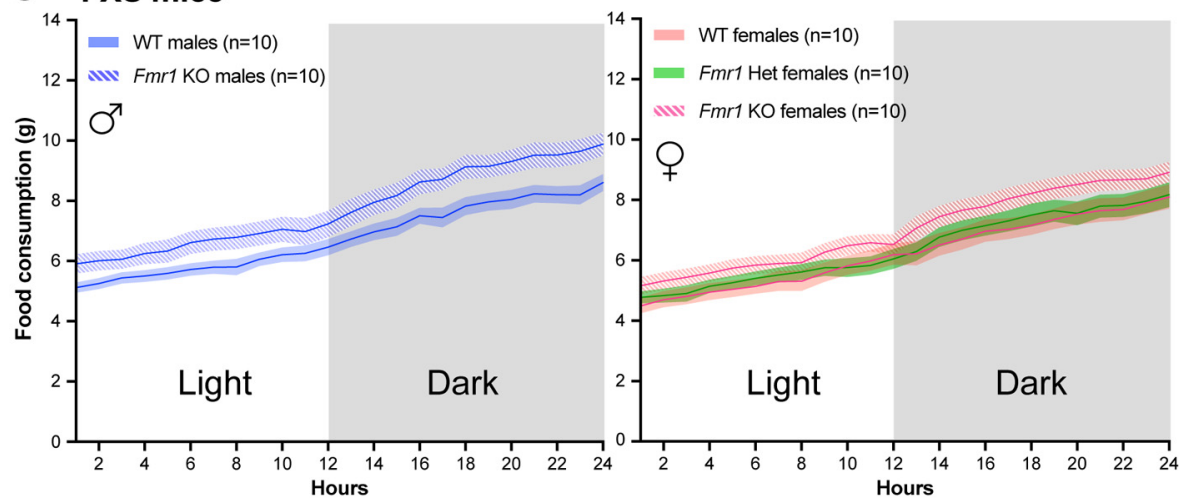

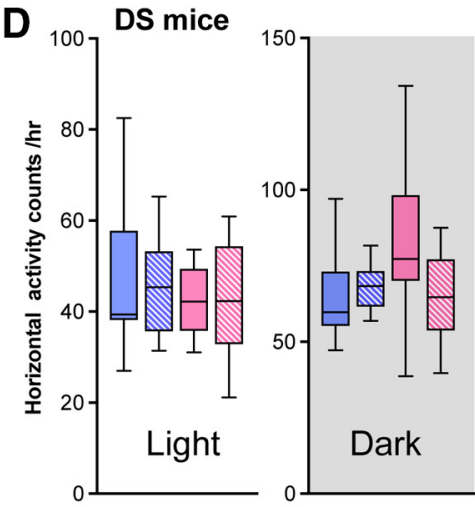

E

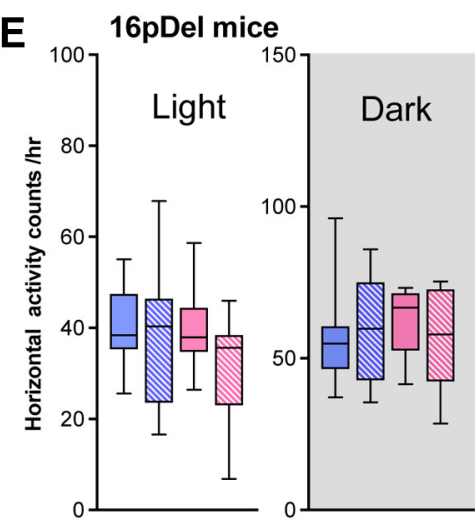

$\mathbf{F}$

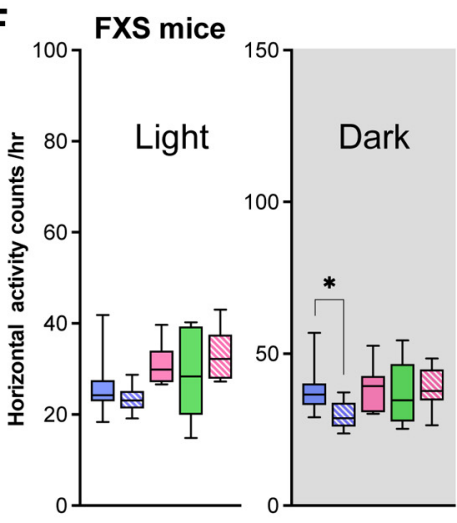

Figure 2. Cumulative food consumption and activity levels of DS, 16pDel, and FXS mice measured in CLAMS. $\boldsymbol{A}-\boldsymbol{C}$, Average cumulative food consumption in grams shown over a 24-h cycle for WT and Dp(16)Yey/+ male and female mice (A); WT and 16p11.2df/+ male and female mice (B); WT and Fmr1 KO (homo/heterozygous) male and female mice (C). $\boldsymbol{D}-\boldsymbol{F}$, Activity levels (horizontal beam breaks) in CLAMS cages for WT and Dp(16)Yey/+ male and female mice (D); WT and 16p11.2 df/+ male and female mice (E); WT and $F m r 1 \mathrm{KO}$ (homo/heterozygous) male and female mice $(\boldsymbol{F})$. The night phase of testing is depicted by gray shaded area. WT, wild type; DS, Down syndrome; 16pDel, 16p11.2 deletion syndrome; FXS, fragile X syndrome. Data are whisker boxes (min to max, center line indicating median) in $\boldsymbol{A}-\boldsymbol{C}$, or mean \pm SEM in $\boldsymbol{D}-\boldsymbol{F}\left(n=10\right.$ animals per group); ${ }^{*} p<0.05$ (two-way ANOVA and Sidak's post hoc test). 3 : males; ; females.

normalized and lean mass-normalized $\mathrm{VCO}_{2}$ values appeared higher in $16 p 11.2^{d f /+}$ males at night compared with WT littermates (Fig. 4E,H). In absolute values, $\mathrm{Fmr1}^{-1-}$ females displayed higher $\mathrm{VCO}_{2}$ compared with their WT counterparts throughout the 24-h cycle (Fig. 4C). However, normalized $\mathrm{VCO}_{2}$ values revealed that $F \mathrm{mr}^{-/-}$females have significantly reduced $\mathrm{CO}_{2}$ production compared with WT littermates (Fig. 4F,I). These data demonstrate that genetic variations associated with DS, $16 \mathrm{pDel}$, and FXS lead to distinct rates of $\mathrm{CO}_{2}$ production and that these phenotypes are sex specific.

Obtaining $\mathrm{VO}_{2}$ and $\mathrm{VCO}_{2}$ allows for calculation of the respiratory exchange $\left(\mathrm{RER}=\mathrm{VCO}_{2} / \mathrm{VO}_{2}\right)$, which indicates the preferred metabolic substrate. An RER value near 1 is indicative of predominant usage of carbohydrates as energy substrates (Ramos-Jimenez et al., 2008; Farinatti et 


\section{DS mice}

A Absolute values

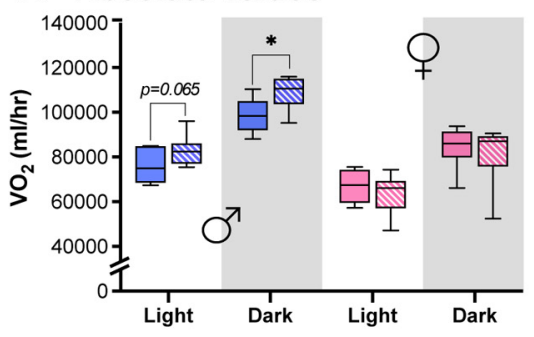

D Body weight-normalized

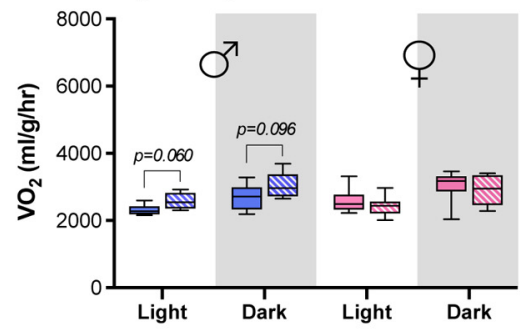

G Lean mass-normalized

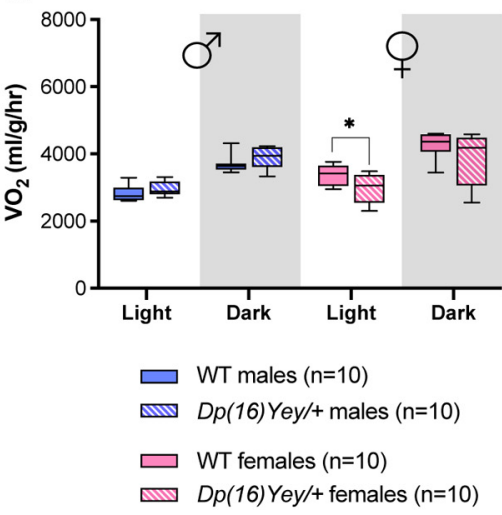

16pDel mice

B Absolute values

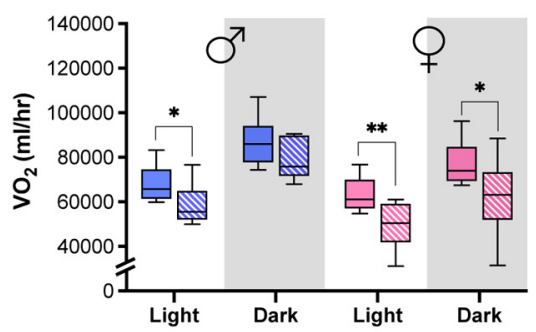

E Body weight-normalized

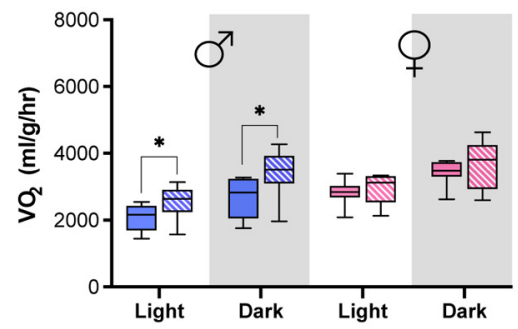

H Lean mass-normalized

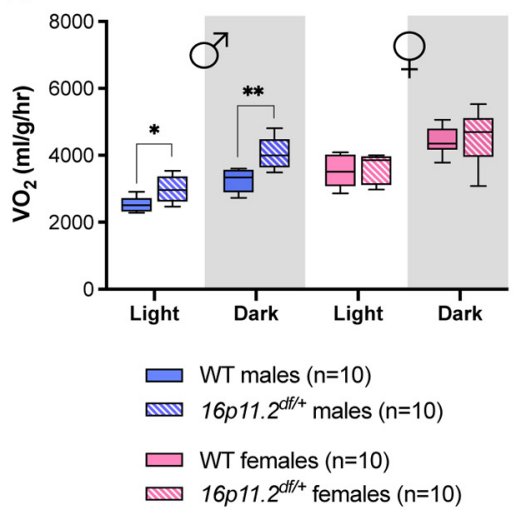

FXS mice

\section{Absolute values}

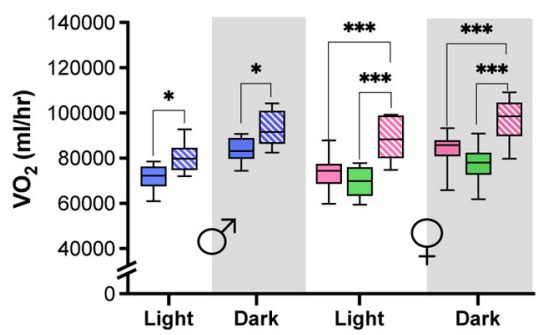

F Body weight-normalized

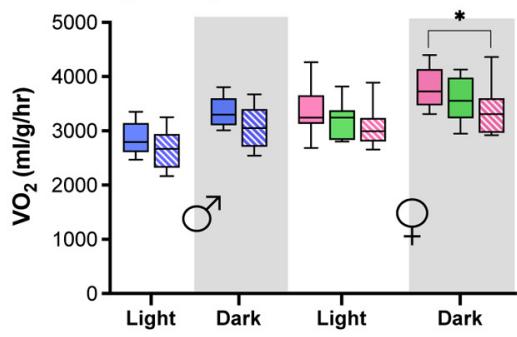

I Lean mass-normalized

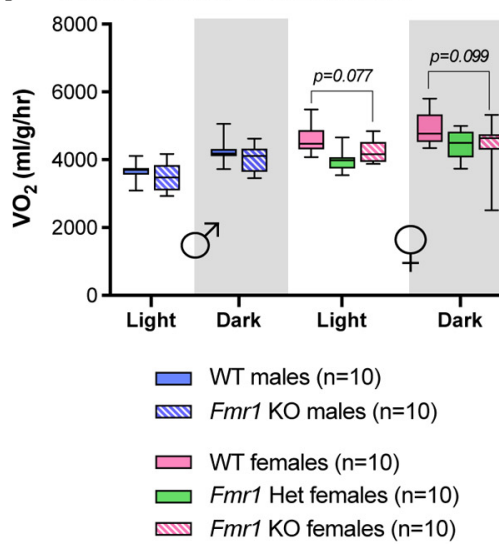

Figure 3. $\mathrm{VO}_{2}$ by DS, $16 \mathrm{pDel}$, and FXS mice measured in CLAMS. $\boldsymbol{A}-\boldsymbol{C}$, Absolute values of average $\mathrm{VO}_{2}$ during day (light) and night (dark) in WT and $D p(16) Y e y /+$ male and female mice $(\boldsymbol{A})$; WT and $16 p 11.2^{\text {df/+ }}$ male and female mice (B); WT and Fmr1 KO (homo/ heterozygous) male and female mice (C). $\boldsymbol{D}-\boldsymbol{F}$, Average $\mathrm{VO}_{2}$ during day and night normalized to body weight in WT and $D p(16) Y e y /+$ male and female mice $(\boldsymbol{D}) ; \mathrm{WT}$ and $16 p 11.2^{\mathrm{df} /+}$ male and female mice $(\boldsymbol{E}) ; \mathrm{WT}$ and Fmr1 KO (homo/heterozygous) male and female mice $(\boldsymbol{F})$. $\mathbf{G}-\boldsymbol{I}$, Average $\mathrm{VO}_{2}$ during day and night normalized to lean mass in WT and $D p(16) Y e y /+$ male and female mice (G); WT and $16 p 11.2^{d f /+}$ male and female mice $(\boldsymbol{H})$; WT and Fmr1 KO (homo/heterozygous) male and female mice (I). The night phase of testing is depicted by gray shaded areas. WT, wild type; DS, Down syndrome; 16pDel, 16p11.2 deletion syndrome; FXS, fragile X syndrome. Data are whisker boxes (min to max, center line indicating median); $n=10$ animals per group. Asterisks depict significant differences between groups; ${ }^{*} p<0.05,{ }^{* *} p<0.01,{ }^{* \star *} p<0.001$ (two-way ANOVA and Sidak's post hoc test); $p$ value is indicated when approaching significance. 3 : males; ;

al., 2016; Coffman et al., 2019; Patel et al., 2020). All mice housed in the CLAMS for this study displayed an RER of $\sim 1$ and below, consistent with low-to-moderate activity (Fig. 5). During their inactive (light) phase, male and female $D p(16) Y e y /+$ mice displayed a significantly lower RER than their WT counterparts (Fig. 5A). No significant difference in RER was detected between WT and 16p11.2 $2^{d f /+}$ mice (Fig. 5B), whereas $\mathrm{Fmr1}^{-1-}$ females displayed a lower average RER during the day compared with WT females (Fig. 5C). These data reveal distinct sex-specific effects of genetic variations on basal energy metabolism in the DS, 16pDel, and FXS mouse models.
Finally, the CLAMS monitors heat produced by the animals (in kilocalories per hour) as an indicator of CE. In the DS mouse model, females displayed slightly lower CE compared with males in absolute values (Fig. $6 A$ ). Interestingly, $D p(16)$ Yey/+ females showed significantly reduced CE compared with $\mathrm{WT}$ females when values were normalized to lean mass (Fig. 6G). In absolute values, 16p11.2 $2^{d f /+}$ mice displayed reduced CE compared with sex-matched WT littermates (Fig. $6 B$ ). However, when normalized to body weight or lean mass, 16p11.2 df/+ males displayed increased CE (Fig. 6E,H). $\mathrm{Fmr}^{-1-}$ mice displayed significantly higher absolute CE compared with WT littermates, a phenotype again more 


\section{DS mice}

A Absolute values

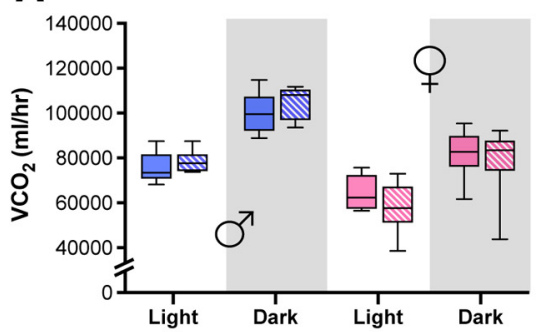

D Body weight-normalized

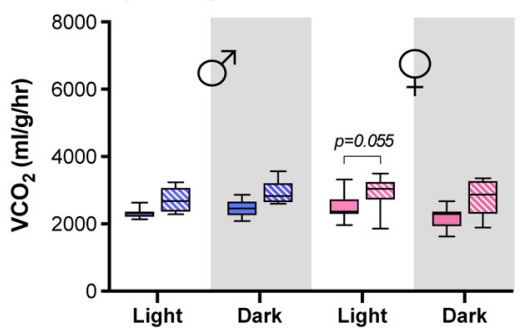

G Lean mass-normalized

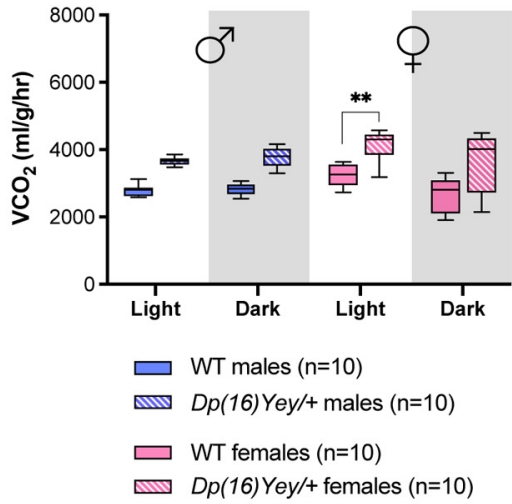

16pDel mice

B Absolute values

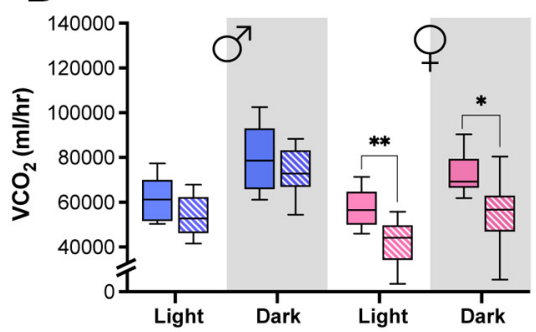

E Body weight-normalized

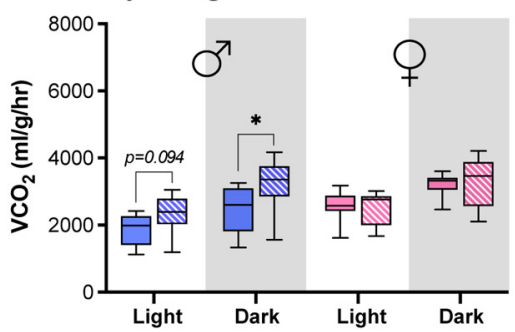

H Lean mass-normalized

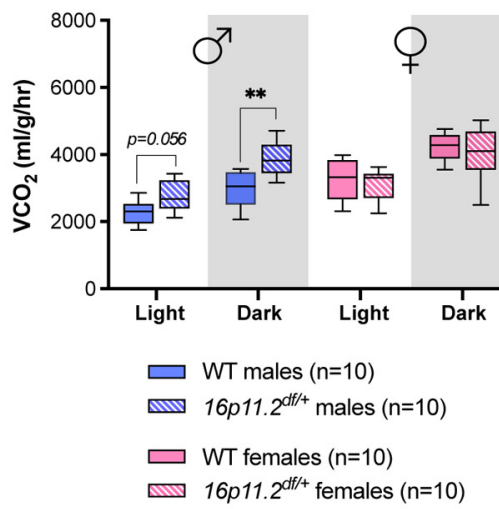

FXS mice

C Absolute values

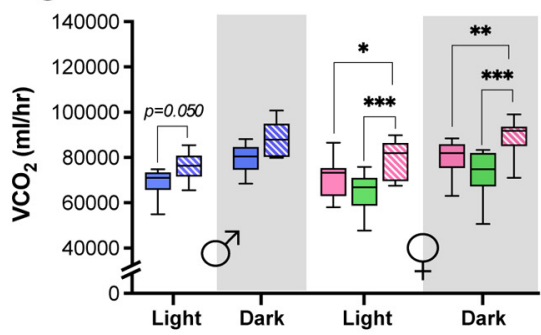

F Body weight-normalized

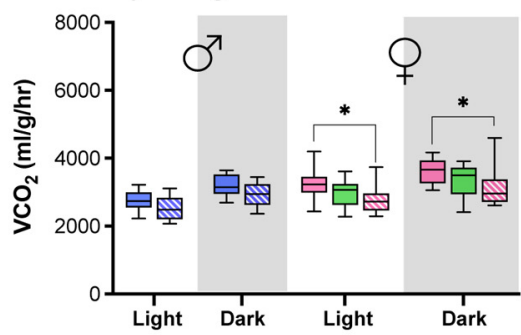

I Lean mass-normalized

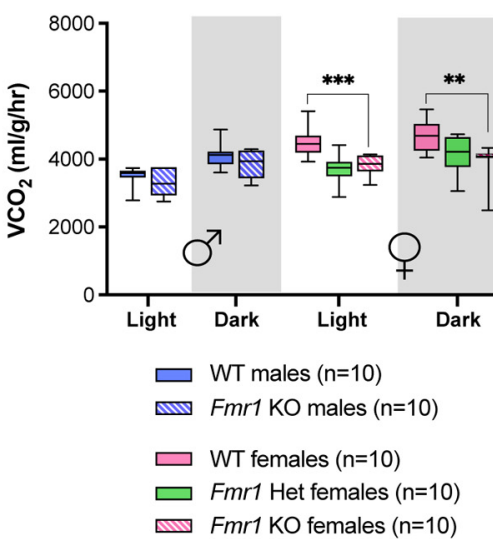

Figure 4. $\mathrm{VCO}_{2}$ by DS, $16 \mathrm{pDel}$, and FXS mice measured in CLAMS. $\boldsymbol{A}-\boldsymbol{C}$, Absolute values of average $\mathrm{VCO}_{2}$ during day (light) and night (dark) in WT and Dp(16)Yey/+ male and female mice (A); WT and 16p11.2 df/+ male and female mice (B); WT and Fmr1 KO (homo/heterozygous) male and female mice (C). $\boldsymbol{D}-\boldsymbol{F}$, Average $\mathrm{VCO}_{2}$ during day and night normalized to body weight in WT and $D p(16) Y e y /+$ male and female mice (D); WT and 16p11.2 $2^{\mathrm{df} /+}$ male and female mice (E); WT and Fmr1 KO (homo/heterozygous) male and female mice $(\boldsymbol{F})$. G-I, Average $\mathrm{VCO}_{2}$ during day and night normalized to lean mass in WT and $D p(16) Y e y /+$ male and female mice (G); WT and 16p11.2 df/+ male and female mice $(\boldsymbol{H})$; WT and Fmr1 KO (homo/heterozygous) male and female mice (I). The night phase of testing is depicted by gray shaded areas. WT, wild type; DS, Down syndrome; 16pDel, $16 \mathrm{p} 11.2$ deletion syndrome; FXS, fragile X syndrome. Data are whisker boxes (min to max, center line indicating median); $n=10$ animals per group. Asterisks depict significant differences between groups; ${ }^{*} p<0.05$, ${ }^{\star \star} p<0.01$, ${ }^{\star \star \star} p<0.001$ (twoway ANOVA and Sidak's post hoc test); $p$ value is indicated when approaching significance. 0 : males; $;$ : females.

pronounced in females (Fig. 6C). However, when normalized to body weight or lean mass, $\mathrm{Fmr1}^{-1-}$ females displayed significantly reduced CE (Fig. 6F,I). These results demonstrate that the DS, 16pDel, and FXS mouse models display distinct, sex-specific levels of $\mathrm{CE}$.

\section{Plasma metabolites measured by LC-MS in DS, $16 \mathrm{pDel}$, and FXS mice}

Since the above-mentioned findings suggested sexspecific alterations in basal energy metabolism, and as recent studies have linked NDD to alterations in plasma metabolites related to one-carbon and energy metabolism
(Gross et al., 2019; Orozco et al., 2019), we next sought to identify differences in circulating metabolites related to mitochondrial function in all three mouse models. Using targeted metabolomics by LC-MS, we measured the levels of key plasma metabolites related to the tricarboxylic acid (TCA) cycle in three independent batches (DS, 16pDel, and FXS mice; Figs. 7-9). These metabolites include intermediates of the TCA cycle (e.g., citrate, cis-aconitate and $\alpha$-ketoglutarate) as well as anaplerotic metabolites that replenish the TCA cycle intermediates (e.g., pyruvate, aspartate, glutamate). Blood plasma was collected in the fed state to match CLAMS analyses that were performed with free access to food and water. 

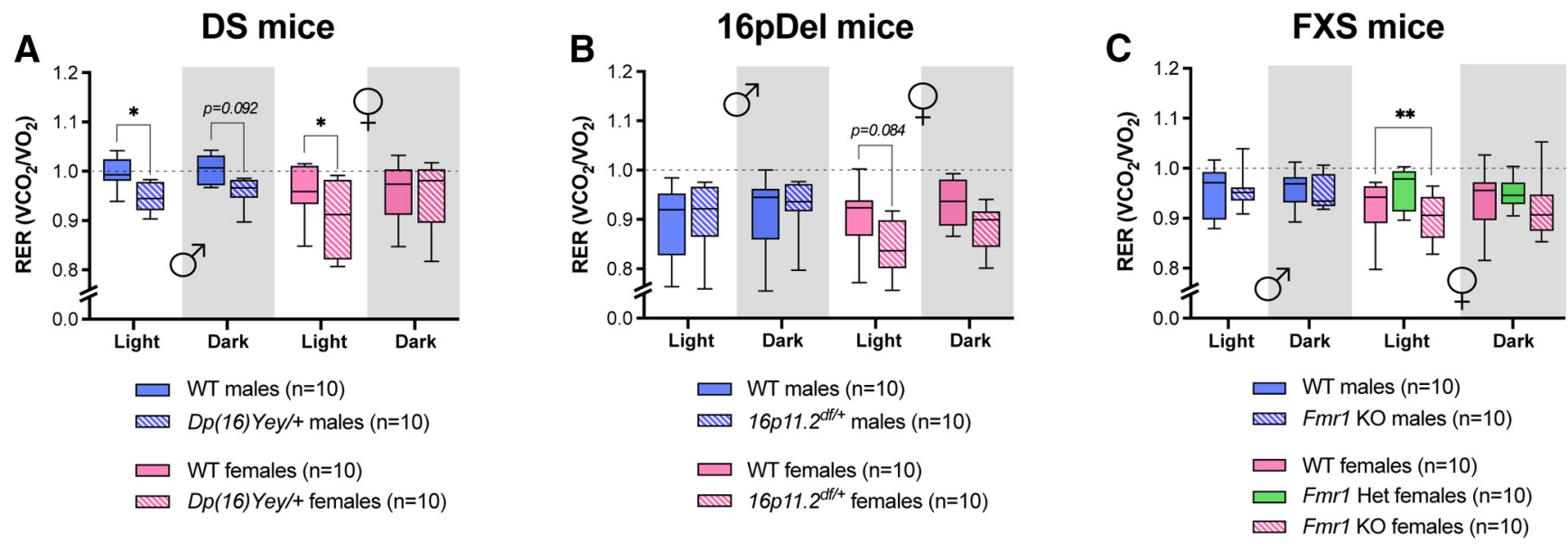

Figure 5. RER from DS, 16pDel, and FXS mice. A-C, RER calculated from absolute values during day (light) and night (dark) in WT and $D p(16) Y e y /+$ male and female mice (A); WT and 16p11.2 ${ }^{d f /+}$ male and female mice (B); WT and Fmr1 KO (homo/heterozygous) male and female mice $(\boldsymbol{C})$. The night phase of testing is depicted by gray shaded areas. The dotted line depicts a RER of 1 . WT, wild type; DS, Down syndrome; 16pDel, 16p11.2 deletion syndrome; FXS, fragile X syndrome. Data are whisker boxes (min to max, center line indicating median); $n=10$ animals per group. Asterisks depict significant differences between groups; ${ }^{*} p<0.05$, ${ }^{* *} p<0.01$ (two-way ANOVA and Sidak's post hoc test); $p$ value is indicated when approaching significance. ${ }^{*}$ : males; + : females.

When compared with their respective sex-matched WT littermates, $D p(16) Y e y /+$ females displayed significantly lower levels of cis-aconitate, while $D p(16) Y e y /+$ males exhibited higher concentration of glutamate, asparagine and proline (Fig. 7). Compared with $D p(16) Y e y /+$ females, $D p$ (16)Yey/+ males displayed higher levels of cis-aconitate, succinate, proline, and acetyl carnitine (Fig. 7).

When compared with their WT counterparts, 16p11.2 $2^{\mathrm{df} / \mathrm{+}}$ females did not show any change, while $16 p 11.2^{\mathrm{dft}+\mathrm{t}}$ males displayed significantly higher plasma concentrations of glutamate, aspartate and asparagine (Fig. 8). 16p11.2 $\mathrm{df/+}$ males also displayed higher levels of aspartate and asparagine compared with 16p11.2 ${ }^{\text {df/+ }}$ females (Fig. 8).

Finally, compared with their respective sex-matched WT littermates both $\mathrm{Fmr1}^{-1-}$ males and females displayed significantly elevated levels of glutamine, asparagine and carnitine (Fig. 9). Fmr1 KO males also displayed a significant increase in glutamate, aspartate, proline, and carnitine compared with their WT counterparts. Fmr1 ${ }^{-1-}$ females showed significantly lower levels of fumarate, malate, glutamate, and aspartate than $\mathrm{Fmr}^{-1-}$ males (Fig. 9).

\section{Discussion}

Together, our study provides the first systematic characterization of basal metabolism in mouse models of DS, $16 \mathrm{pDel}$, and FXS, revealing that these models display distinct, sex-specific basal metabolic signatures with minimal influence of physical activity and independent of the number of calories consumed.

Activity data obtained in our study do not necessarily reflect the hyperactivity phenotypes commonly found among human or rodent NDDs, a discrepancy most likely because of our experimental setup. Indeed, the CLAMS consists of relatively small individual cages, limiting animal mobility. For instance, in a normal home cage environment, male and female $16 p 11.2^{d f /+}$ mice are hyperactive (Horev et al., 2011; Ouellette et al., 2020), and the majority of $16 \mathrm{p} 11.2$ deletion human carriers display hyperactivity (Miller et al., 2009). However, the limited space offered by CLAMS cages serves to control for metabolic measures, enabling accurate assessment of basal metabolism independent of activity. Of note, whereas hyperactivity is a common feature among individuals with NDDs, they are, however, less likely to engage in physical activity (Vis et al., 2009; Mendonca et al., 2010; Mazurek and Wyka, 2015), partly because of a lack of social skills necessary to participate in group-based physical activities (Foerste et al., 2016).

Results obtained from the DS mouse model suggest that differences in metabolism arise from the DS genotype independent of important factors that influence metabolism, including activity levels and food intake. Pronounced differences were found between mutant $(D p(16) Y e y /+)$ males and females, bolstering the importance of sex differences in DS research. Sex differences in human DS include higher disease penetrance among males and high rates of congenital heart defects and increased abdominal adiposity in females (Sobey et al., 2015; Flygare Wallén et al., 2018). Our results also suggest that DS phenotypes are more severe in male mice. The fact that $D p$ (16)Yey/+ mice modeling DS do not display differences in weight and lean mass in our study also highlights an important discrepancy with the human syndrome. This could reflect the particular DS mouse model used, since $D p(16) Y e y /+$ mice only possess trisomy of $\sim 66 \%$ of Hsa21 gene orthologues (Li et al., 2007; Roubertoux and Carlier, 2010; Yu, 2010; Herault et al., 2017). The other Hsa21 gene orthologues for the mouse are present on Mmu 10 and 17. Although Hsa21 is syntenic with portions of three mouse chromosomes, trisomy of those genes present on Mmu 16 (113 genes) is generally considered a reliable model of human DS cognitive, physical and behavioral phenotypes. The lack of differences in weight 


\section{DS mice}

A Absolute values

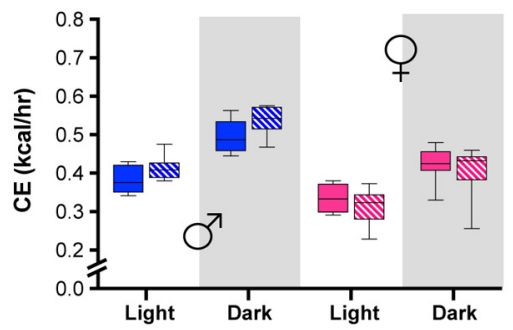

D Body weight-normalized

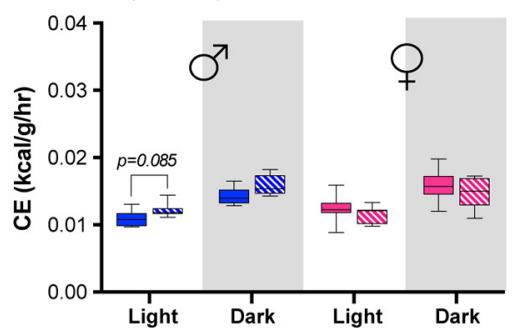

G Lean mass-normalized

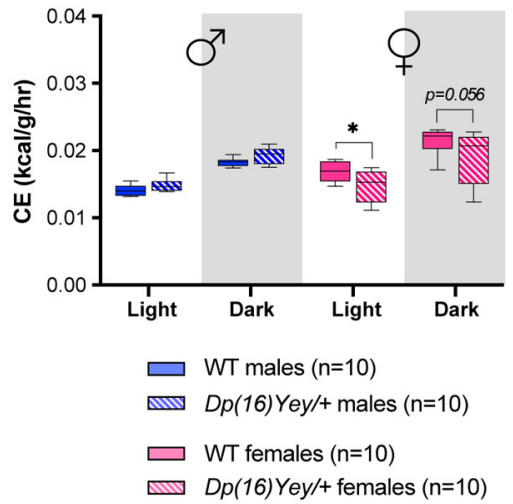

16pDel mice

B Absolute values

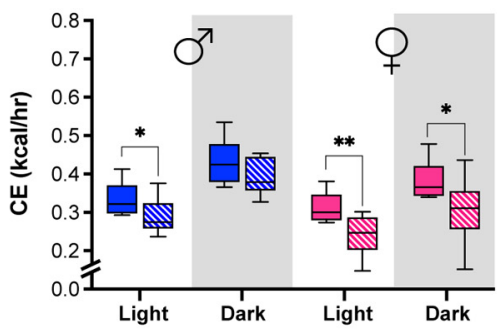

E Body weight-normalized

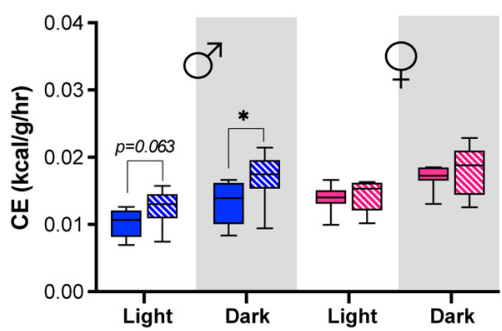

H Lean mass-normalized

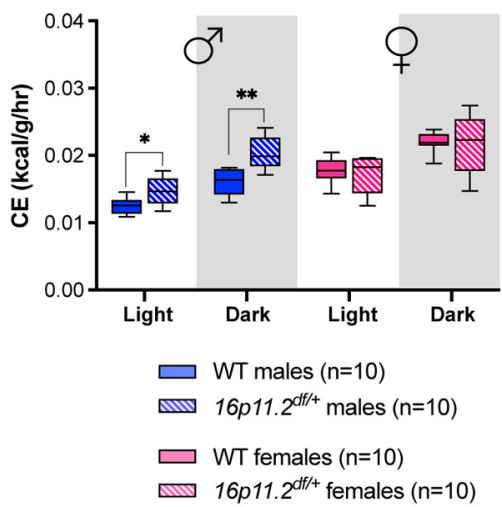

FXS mice

C Absolute values

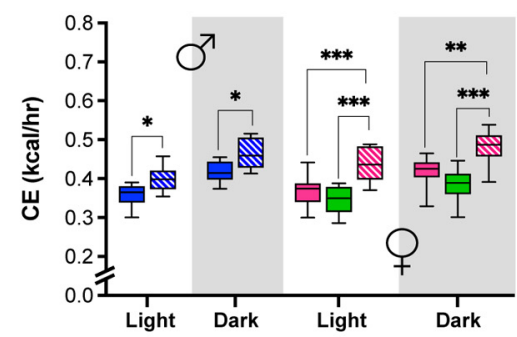

F Body weight-normalized

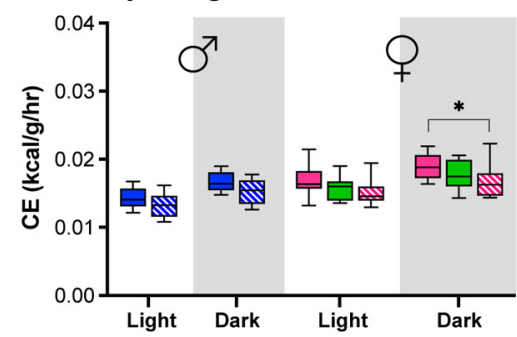

I Lean mass-normalized

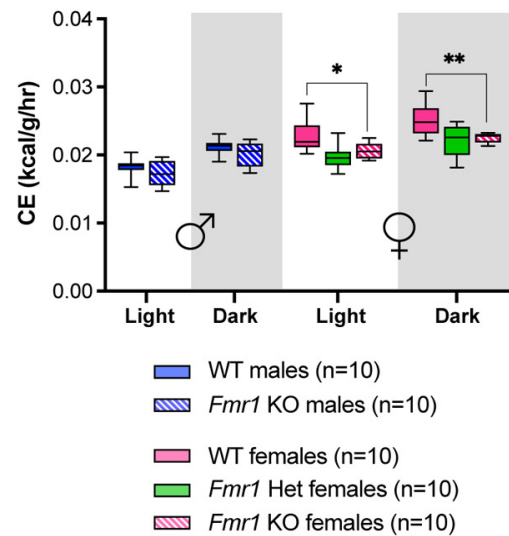

Figure 6. CE by DS, 16pDel, and FXS mice measured in CLAMS. $\boldsymbol{A}-\boldsymbol{C}$, Absolute values of average CE during day (light) and night (dark) in WT and Dp(16)Yey/+ male and female mice (A); WT and 16p11.2df/+ male and female mice (B); and WT and Fmr1 KO (homo/heterozygous) male and female mice (C). $\boldsymbol{D}-\boldsymbol{F}$, Average CE during day and night normalized to body weight in WT and $D p(16)$ Yey/+ male and female mice (D); WT and 16p11.2 ${ }^{\text {dff } /+}$ male and female mice (E); and WT and Fmr1 KO (homo/heterozygous) male and female mice $(\boldsymbol{F})$. G-I, Average CE during day and night normalized to lean mass in WT and $D p(16) Y e y /+$ male and female mice (G); WT and 16p11.2 ${ }^{d f /+}$ male and female mice $(\boldsymbol{H})$; and WT and Fmr1 KO (homo/heterozygous) male and female mice (I). The night phase of testing is depicted by gray shaded areas. WT, wild type; DS, Down syndrome; 16pDel, 16p11.2 deletion syndrome; FXS, fragile $X$ syndrome. Data are whisker boxes ( $\min$ to $\max$, center line indicating median); $n=10$ animals per group. Asterisks depict significant differences between groups; ${ }^{*} p<0.05,{ }^{* *} p<0.01,{ }^{* \star *} p<0.001$ (two-way ANOVA and Sidak's post hoc test). ${ }^{\star}$ : males; : females.

and lean mass in the $D p(16) Y e y /+$ mice could suggest that the genes linked to human DS-associated obesity are present in regions of synteny on Mmu17 or Mmu10. However, body proportions of a DS mouse model harboring trisomy of all Hsa21 syntenic regions found small but significant reductions in body length and weight ( $\mathrm{Yu}$, 2010), again in discordance with human DS body proportions (Vis et al., 2009; Shields et al., 2017).

The 16p11.2df/+ mutation also had an influence on metabolism, yet distinct from the other NDD models used in this study. Results in $16 p 11.2^{d f /+}$ mice were also independent of activity levels and food consumption.
Although $16 p 11.2^{d f /+}$ mice accurately embody numerous phenotypes reminiscent of the human syndrome, interpretation of metabolic data must be made in light of the opposite body proportions often observed between mutant mice and human carriers (Horev et al., 2011; Portmann et al., 2014; Arbogast et al., 2016). Indeed, human $16 \mathrm{pDel}$ is associated with obesity, whereas $16 p 11.2^{d f /+}$ mice display a propensity for leanness (Horev et al., 2011; Portmann et al., 2014; Arbogast et al., 2016), particularly in females as confirmed by our study.

Finally, $\mathrm{Fmr}^{-1-}$ mice also displayed a metabolic phenotype distinct from the DS and $16 \mathrm{pDel}$ mouse models. 
$\square$ WT males $(n=5)$

$D p(16) Y e y /+$ males $(\mathrm{n}=5)$

$\square$ WT females $(\mathrm{n}=6) \quad D p(16)$ Yey/ females $(\mathrm{n}=6$

Lactate

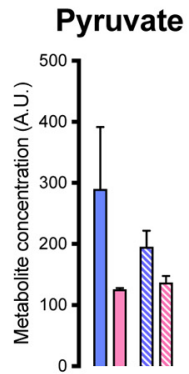

Glutamate
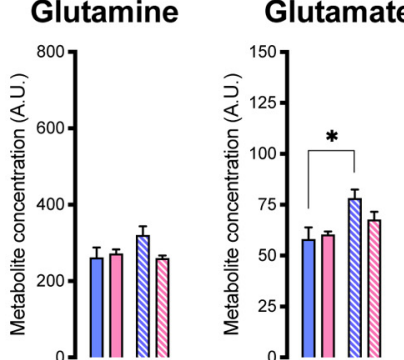

Citrate
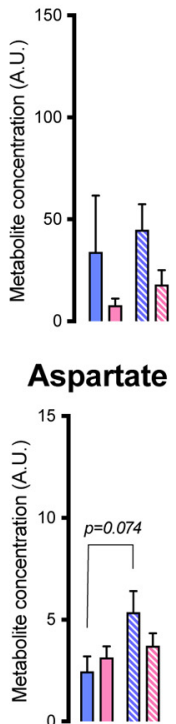

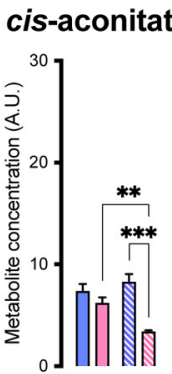

Asparagine
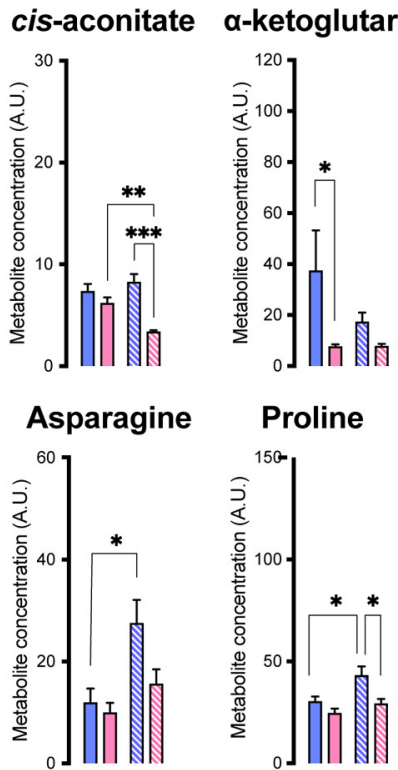

Proline

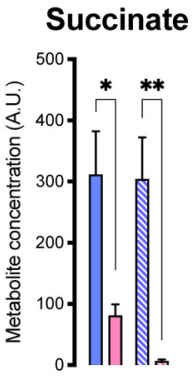

Creatine

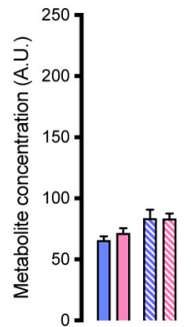

\section{Fumarate}

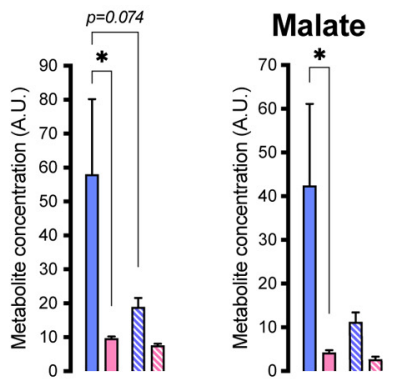

Carnitine Acetyl Carnitine
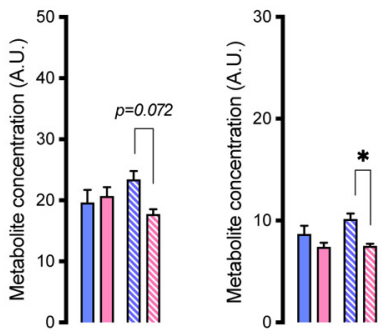

Figure 7. Plasma metabolite levels in DS mice measured by LC-MS. WT, wild type. Data are mean \pm SEM; $n=5-6$ animals per group. Asterisks depict significant differences between groups; ${ }^{*} p<0.05,{ }^{* *} p<0.01,{ }^{* * *} p<0.001$ (two-way ANOVA and Tukey's post hoc test).

The Fmr1 mutation was associated with an increase in body weight and altered all physiological indices examined in this study. Interestingly, heterozygous $F m r 1^{+/-}$female mice displayed similar metabolic signatures as WT $\left(F m r 1^{+/+}\right)$females and males, as expected from compensation by the remaining WT allele (Hoogeveen and Oostra,
1997; Linden et al., 1999; McLennan et al., 2011; Bartholomay et al., 2019).

Remarkably, the $16 \mathrm{pDel}$ and FXS mouse models displayed largely contrasting phenotypes. The $16 \mathrm{pDel}$ and FXS mouse models also exhibited larger changes in metabolic phenotypes among females compared with males. $\square$ WT males $(n=5)$
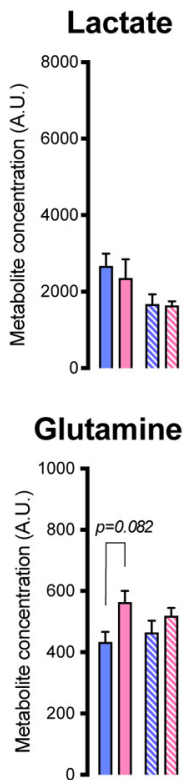

$16 p 11.2^{d f /+}$ males $(n=5)$

Pyruvate
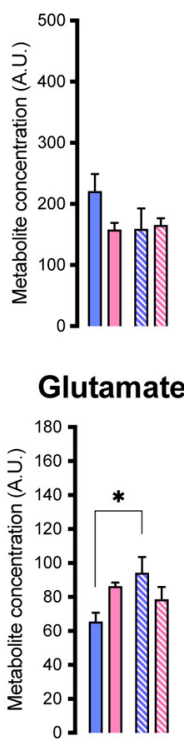

Citrate

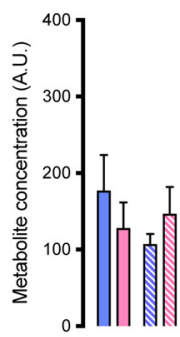

Aspartate

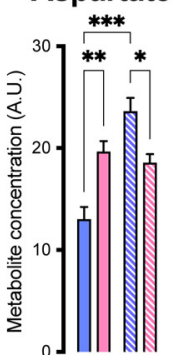

$\square$ WT females $(n=5)$

$16 p 11.2^{d f / t}$ females $(n=5)$

Figure 8. Plasma metabolite levels in $16 \mathrm{pDel}$ mice measured by LC-MS. WT, wild type. Data are mean \pm SEM; $n=5$ animals per group. Asterisks depict significant differences between groups; ${ }^{*} p<0.05,{ }^{* \star} p<0.01,{ }^{* \star *} p<0.001$ (two-way ANOVA and Tukey's post hoc test). 
$\square$ WT males $(n=5)$
Fmr1 KO males $(\mathrm{n}=5)$
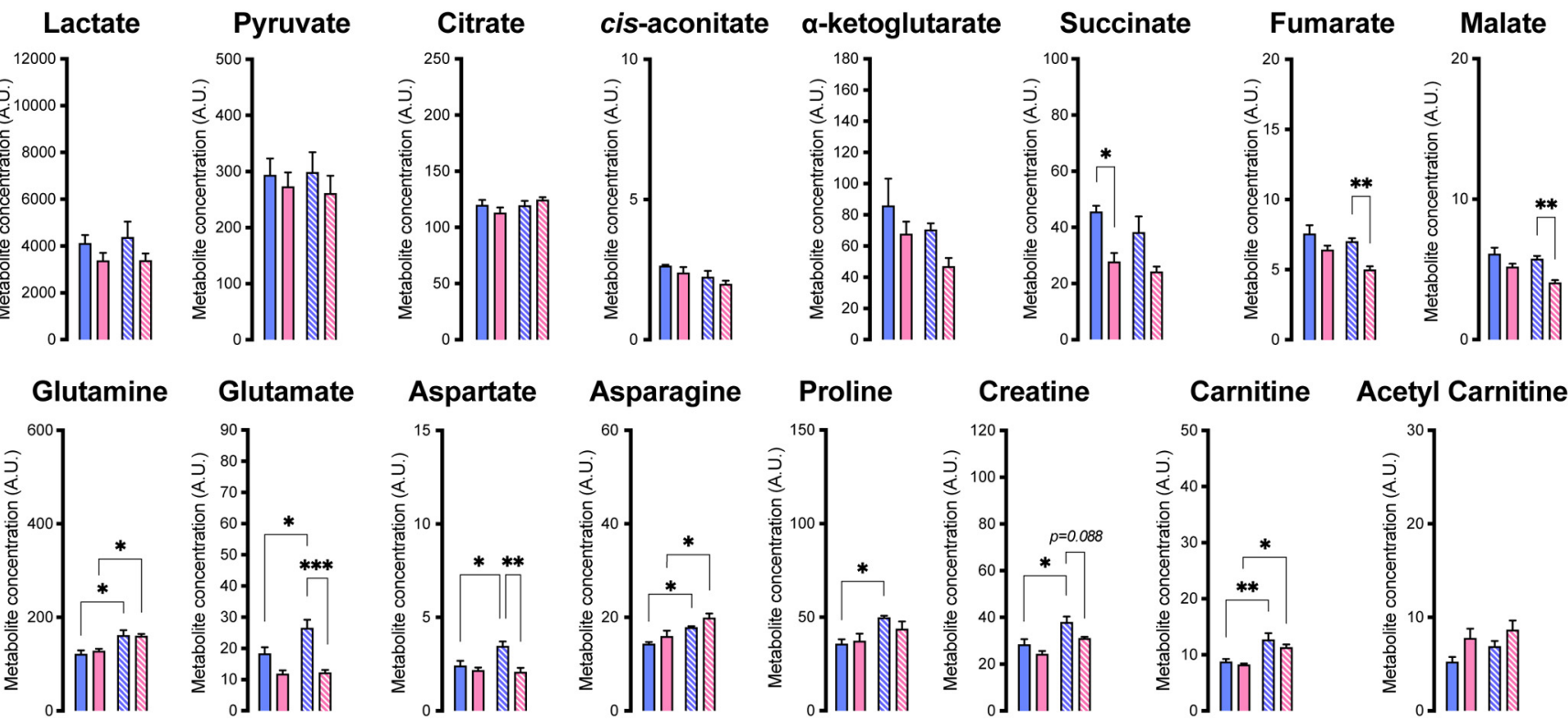

Figure 9. Plasma metabolite levels in FXS mice measured by LC-MS. WT, wild type. Data are mean \pm SEM; $n=5$ animals per group. Asterisks depict significant differences between groups; ${ }^{*} p<0.05,{ }^{* *} p<0.01,{ }^{* * *} p<0.001$ (two-way ANOVA and Tukey's post hoc test).

Both the DS and 16pDel mouse models demonstrated metabolic difference among males and females, regardless of genotype. This could be an effect of the background strain of these mouse models, which used a mixed B6/129 background, whereas the FXS mouse model used a mixed FVB/129 background.

In line with sex-specific and model-specific alterations in body composition and metabolic phenotypes, our metabolomic data suggest significant changes in mitochondrial metabolism. First, many changes were observed for TCA intermediates downstream of citrate (e.g., cis-aconitate and succinate in DS mice) to suggest that the first TCA reaction, i.e., condensation of oxaloacetate with acetyl-CoA catalyzed by citrate synthase, is not affected. In agreement, circulating levels of pyruvate and acetyl carnitine were mostly similar in males and females whatever the mouse model and mutation. Second, some TCA intermediates were highly different between male and female WT littermates of the $D p(16) Y e y /+$ strain (e.g., succinate, fumarate, and malate), while they were unchanged in the plasma of the other WT strains. This suggests that interstrain differences of the genetic backgrounds could contribute to these observations. Third, important differences were observed in the levels of anaplerotic substrates in males of each mouse model. The mutations led to increased levels of anaplerotic amino acids including glutamate, aspartate and asparagine in the three mouse models as well as increased proline in Dp(16)Yey/+ and $F m r 1^{-1-}$ males. Interestingly, this pattern was not related to differences in body weight or lean mass (a main source of amino acids) since each model showed either unchanged (Fig. 1A), decreased (Fig. 1B), or increased (Fig. $1 C)$ body weight and lean mass. Increased levels of plasma anaplerotic amino acids could result from increased muscular proteolysis, decreased glucogenesis and/or decreased oxidation and anaplerotic influx in the TCA cycle (Chang and Goldberg, 1978; Owen et al., 2002). Interestingly, altered plasma levels of glutamate, aspartate and asparagine have been associated with prediabetes (Owei et al., 2019) as well as coronary heart disease and type 2 diabetes in human subjects (Ottosson et al., 2018). Although it is premature to speculate based on plasma metabolite levels, which metabolic pathway(s) are affected and whether or not mitochondrial anaplerotic flux is altered, our findings highlight major sex-specific and mutation-specific differences in TCA cycle metabolites and anaplerotic amino acids.

Our findings bring forward the concept of NDD-associated metabolic disturbances and support NDD mouse models as valuable tools to gain novel insight into this understudied association. Providing novel insight into NDD-associated metabolic alterations is an essential prerequisite for future preclinical and clinical investigations. Because of similarities in phenotypic expression, NDDs are generally treated as homogeneous groups, neglecting their unique genetic variations. Our results challenge this idea by demonstrating the influence of genetics despite similarities in overt expression of symptoms. This suggests that personalized clinical interventions may be required to address unique NDD-associated metabolic abnormalities depending on both genetic cause and sex.

Insights into basal metabolic function in live animals will provide a basis for future studies aimed at understanding mechanisms underlying metabolic dysfunction in NDDs, and/or aimed at detecting changes in response to intervention. 


\section{References}

Arch J, Hislop D, Wang S, Speakman J (2006) Some mathematical and technical issues in the measurement and interpretation of open-circuit indirect calorimetry in small animals. Int $\mathrm{J}$ Obes (Lond) 30:1322-1331.

Arbogast T, Ouagazzal A, Chevalier C, Kopanitsa M, Afinowi N, Migliavacca E, Cowling B, Birling M, Champy M, Reymond A, Herault Y (2016) Reciprocal effects on neurocognitive and metabolic phenotypes in mouse models of $16 \mathrm{p} 11.2$ deletion and duplication syndromes. PLoS Genet 12:e1005709.

Bakker C, Vereij C, Willemsen R, van der Helm R, Oerlemans F, Vermy M, Bygrave A, Hoogeveen A, Oostra B, Reyniers E, De BK, D'Hooge R, Cras P, van Velzen D, Nagels G, Martin J, De Deyn P, Darby J, Willems P (1994) Fmr1 knockout mice: a model to study fragile $X$ mental retardation. The Dutch-Belgian fragile $X$ consortium. Cell 78:23-33.

Bartholomay K, Lee C, Bruno J, Lightbody A, Reiss A (2019) Closing the gender gap in fragile $X$ syndrome: review on females with FXS and preliminary research findings. Brain Sci 9:11.

Bertapelli F, Pitetti K, Agiovlasitis S, Guerra-Junior G (2016) Overweight and obesity in children and adolescents with Down syndrome-prevalence, determinants, consequences, and interventions: a literature review. Res Dev Disabil 57:181-192.

Coffman K, Cheuvront N, Salgado R, Kenefick R (2019) Biological variation of resting measures of ventilation and gas exchange in a large healthy cohort. Eur J Appl Physiol 119:2033-2040.

Chang TW, Goldberg AL (1978) The metabolic fates of amino acids and the formation of glutamine in skeletal muscle. J Biol Chem 253:3685-3693.

Crabbe LS, Bensky AS, Hornstein L, Schwartz DC (1993) Cardiovascular abnormalities in children with fragile $X$ syndrome. Pediatrics 91:714-715.

Croen L, Zerbo O, Qian Y, Massolo M, Rich S, Sidney S, Kripke C (2015) The health status of adults on the autism spectrum. Autism 19:814-823.

Dahlhaus $R$ (2018) Of men and mice: modeling the fragile $X$ syndrome. Front Mol Neurosci 11:41.

Farinatti P, Castinheiras Neto A, Amorim P (2016) Oxygen consumption and substrate utilization during and after resistance exercises performed with different muscle mass. Int J Exerc Sci 9:77-88.

Flygare Wallén E, Ljunggren G, Carlsson AC, Pettersson D, Wändell $P$ (2018) High prevalence of diabetes mellitus, hypertension and obesity among persons with a recorded diagnosis of intellectual disability or autism spectrum disorder. J Intellect Disabil Res 62:269-280.

Foerste T, Sabin M, Reid S, Reddihough D (2016) Understanding the causes of obesity in children with trisomy 21 : hyperphagia vs physical inactivity. J Intellect Disabil Res 60:856-864.

Gimeno-Ferrer F, Albuquerque D, Guzmán Luján C, Marcaida Benito G, Torreira Banzas C, Repáraz-Andrade A, Ballesteros Cogollos V, Aleu Pérez-Gramunt M, Galán Gómez E, Quintela I, RodríguezLópez R (2019) The effect of copy number variations in chromosome $16 p$ on body weight in patients with intellectual disability. $J$ Hum Genet 64:221-231.

Gross TJ, Doran E, Cheema AK, Head E, Lott IT, Mapstone M (2019) Plasma metabolites related to cellular energy metabolism are altered in adults with Down syndrome and Alzheimer's disease. Develop Neurobiol 79:622-638.

Gupta R, Ramachandran R, Venkatesan P, Anoop S, Joseph M, Thomas N (2017) Indirect Calorimetry: From Bench to Bedside. Indian J Endocrinol Metab 21:594-599.

Hanson E, Nasir R, Fong A, Lian A, Hundley R, Shen Y, Wu B, Holm I, Miller D; 16p11.2 Study Group Clinicians (2010) Cognitive and behavioral characterization of $16 \mathrm{p} 11.2$ deletion syndrome. J Dev Behav Pediatr 31:649-657.

Herault Y, Delabar J, Fisher E, Tybulewicz V, Yu E, Brault V (2017) Rodent models in Down syndrome research: impact and future opportunities. Dis Model Mech 10:1165-1186.
Hoogeveen A, Oostra B (1997) The fragile X syndrome. J Inherit Metab Dis 20:139-151.

Horev G, Ellegood J, Lerch J, Son Y, Muthuswamy L, Vogel H, Krieger A, Buja A, Henkelman M, Wigler M, Mills A (2011) Dosagedependent phenotypes in models of $16 \mathrm{p} 11.2$ lesions found in autism. Proc Natl Acad Sci USA 108:17076-17081.

Kostopoulou E, Dastamani A, Caiulo S, Antell H, Flanagan S, Shah P (2019) Hyperinsulinaemic hypoglycaemia: a new presentation of 16p11.2 deletion syndrome. Clin Endocrinol (Oxf) 90:766-769.

Leboucher A, Pisani D, Martinez-Gili L, Chilloux J, Bermudez-Martin P, Van Dijck A, Ganief T, Macek B, Becker J, Le Merrer J, Kooy R, Amri E, Khandjian E, Dumas M, Davidovic L (2019) The translational regulator FMRP controls lipid and glucose metabolism in mice and humans. Mol Metab 21:22-35.

Li Z, Yu T, Morishima M, Pao A, LaDuca J, Conroy J, Nowak N, Matsui S, Shiraishi I, Yu Y (2007) Duplication of the entire 22.9 Mb human chromosome 21 syntenic region on mouse chromosome 16 causes cardiovascular and gastrointestinal abnormalities. Hum Mol Genet 16:1359-1366.

Linden M, Tassone F, Gane L, Hills J, Hagerman R, Taylor A (1999) Compound heterozygous female with fragile $X$ syndrome. Am $\mathrm{J}$ Med Genet 83:318-321.

Lovelace J, Ethell I, Binder D, Razak K (2018) Translation-relevant EEG phenotypes in a mouse model of fragile $X$ syndrome. Neurobiol Dis 115:39-48.

Mazurek D, Wyka J (2015) Down syndrome. Genetic and nutritional aspects of accompanying disorders. Rocz Panstw Zakl Hig 66:189-194.

McLennan $Y$, Polussa J, Tassone F, Hagerman R (2011) Fragile $x$ syndrome. Curr Genomics 12:216-224.

Mendonca G, Pereira F, Fernhall B (2010) Reduced exercise capacity in persons with down syndrome: cause, effect, and management. Ther Clin Risk Manag 6:601-610.

Miller DT, Chung W, Nasir R, Shen Y, Steinman K, Wi B, Hanson E (2009) 16p11.2 recurrent microdeletion [Updated 2015 Dec 10]. In: GeneReviews (Adam MP, Ardinger HH, Pagon RA, eds), pp 19932020. Seattle: University of Washington, Seattle.

Mtaweh H, Tuira L, Floh AA, Parshuram CS (2018) Indirect calorimetry: history, technology, and application. Front Pediatr 6:257.

Orozco JS, Hertz-Picciotto I, Abbeduto L, Slupsky CM (2019) Metabolomics analysis of children with autism, idiopathic-developmental delays, and Down syndrome. Transl Psychiatry 9:243.

Ottosson F, Smith E, Melander O, Fernandez C (2018) Altered asparagine and glutamate homeostasis precede coronary artery disease and type 2 diabetes. J Clin Endocrinol Metab 103:3060-3069.

Ouellette J, Toussay X, Comin CH, Costa LDF, Ho M, LacalleAurioles M, Freitas-Andrade M, Liu QY, Leclerc S, Pan Y, Liu Z, Thibodeau JF, Yin M, Carrier M, Morse CJ, Dyken PV, Bergin CJ, Baillet S, Kennedy CR, Tremblay MĖ, et al. (2020) Vascular contributions to 16 p11.2 deletion autism syndrome modeled in mice. Nat Neurosci 23:1090-1101.

Owei I, Umekwe N, Stentz F, Wan J, Dagogo-Jack S (2019) Amino acid signature predictive of incident prediabetes: a case-control study nested within the longitudinal pathobiology of prediabetes in a biracial cohort. Metabolism 98:76-83.

Owen OE, Kalhan SC, Hanson RW (2002) The key role of anaplerosis and cataplerosis for citric acid cycle function. J Biol Chem 277:30409-30412.

Patel H, Menouar MA, Bhardwaj A (2020) Physiology, respiratory quotient [Updated 2020 Apr 29]. In: StatPearls. Treasure Island: StatPearls Publishing. Available from: https://www.ncbi.nlm.nih. gov/books/NBK531494/.

Peretti S, Mariano M, Mazzocchetti C, Mazza M, Pino MC, Verrotti Di Pianella A, Valenti M (2019) Diet: the keystone of autism spectrum disorder? Nutr Neurosci 22:825-839.

Portmann T, Yang M, Mao R, Panagiotakos G, Ellegood J, Dolen G, Bader PL, Grueter BA, Goold C, Fisher E, Clifford K, Rengarajan P, Kalikhman D, Loureiro D, Saw NL, Zhengqui Z, Miller MA, Lerch JP, Henkelman M, Shamloo M, et al. (2014) Behavioral 
abnormalities and circuit defects in the basal ganglia of a mouse model of 16p11.2 deletion syndrome. Cell Rep 7:1077-1092.

Ramos-Jimenez A, Hernandez-Torres R, Torres-Duran P, RomeroGonzalez J, Mascher D, Posadas-Romero C, Juarez-Oropeza M (2008) The respiratory exchange ratio is associated with fitness indicators both in trained and untrained men: a possible application for people with reduced exercise tolerance. Clin Med Circ Respirat Pulm Med 2:1-9.

Real de Asua D, Parra P, Costa R, Moldenhauer F, Suarez C (2014) Evaluation of the impact of abdominal obesity on glucose and lipid metabolism disorders in adults with Down syndrome. Res Dev Disabil 35:2942-2949.

Roubertoux P, Carlier M (2010) Mouse models of cognitive disabilities in trisomy 21 (Down Ssyndrome). Am J Med Genet C Semin Med Genet 154C:400-416.

Shields N, Hussey J, Murphy J, Gormley J, Hoey H (2017) An exploratory study of the association between physical activity, cardiovascular fitness and body size in children with Down syndrome. Dev Neurorehabil 20:92-98.

Sobey C, Judkins C, Sundararajan V, Phan T, Drummond G, Srikanth $V$ (2015) Risk of major cardiovascular events in people with Down syndrome. PLoS One 10:e0137093.

Sumner LW, Amberg A, Barrett D, Beale MH, Beger R, Daykin CA, Fan TW, Fiehn O, Goodacre R, Griffin JL, Hankemeier T, Hardy N, Harnly J, Higashi R, Kopka J, Lane AN, Lindon JC, Marriott P, Nicholls AW, Reily MD, et al. (2007) Proposed minimum reporting standards for chemical analysis Chemical Analysis Working Group (CAWG) Metabolomics Standards Initiative (MSI). Metabolomics 3:211-221.
Tschöp MH, Speakman JR, Arch JR, Auwerx J, Brüning JC, Chan L, Eckel RH, Farese RV Jr, Galgani JE, Hambly C, Herman MA, Horvath TL, Kahn BB, Kozma SC, Maratos-Flier E, Müller TD, Münzberg H, Pfluger PT, Plum L, Reitman ML, Rahmouni K, Shulman GI, Thomas G, Kahn CR, Ravussin E (2011) A guide to analysis of mouse energy metabolism. Nat Methods 9:57-63.

Van Eersel G, Bouwmeester S, Polak M, Verkoeijen P (2017) The misuse of ANCOVA in neuroimaging studies https://doi.org/10.31234/ osf.io/qcsbz.

Vianello E, Dogliotti G, Dozio E, Corsi Romanelli M (2013) Low hearttype fatty acid binding protein level during aging may protect Down syndrome people against atherosclerosis. Immun Ageing 10:2.

Vis J, Duffels M, Winter M, Weijerman M, Cobben J, Huisman S, Mulder B (2009) Down syndrome: a cardiovascular perspective. J Intellect Disabil Res 53:419-425.

Watson LP, Raymond-Barker P, Moran C, Schoenmakers N, Mitchell C, Bluck L, Chatterjee VK, Savage DB, Murgatroyd PR (2014) An approach to quantifying abnormalities in energy expenditure and lean mass in metabolic disease. Eur J Clin Nutr 68:234-240.

Yang M, Mahrt E, Lewis F, Foley G, Portmann T, Dolmetsch R, Portfors C, Crawley J (2015) 16p11.2 deletion syndrome mice display sensory and ultrasonic vocalization deficits during social interactions. Autism Res 8:507-521.

Yu T, Li Z, Jia Z, Clapcote SJ, Liu C, Li S, Asrar S, Pao A, Chen R, Fan N, Carattini-Rivera S, Bechard AR, Spring S, Henkelman RM, Stoica G, Matsui SI, Nowak NJ, Roder JC, Chen C, Bradley A, et al. (2010) A mouse model of Down syndrome trisomic for all human chromosome 21 syntenic regions. Hum Mol Genet 19:2780-2791. 